\title{
Estimating Trade Policy Effects with Structural Gravity
}

\author{
Roberta Piermartini \\ Yoto V. Yotov
}
CESIFO WORKING PAPER NO. 6009
CATEgory 8: Trade Policy
JULY 2016
An electronic version of the paper may be downloaded
- from the SSRN website: Www.SSRN.com
- from the RePEc website: $\quad$ www.RePEc.org
- from the CESifo website: www.CESifo-group.org/wp




\title{
Estimating Trade Policy Effects with Structural Gravity
}

\begin{abstract}
The objective of this manuscript is to serve as a practical guide for estimations with the structural gravity model. After a brief review of the theoretical foundations, we summarize the main challenges with gravity estimations and we review the solutions to address those challenges. Then, we integrate the latest developments in the empirical gravity literature and we offer six recommendations to obtain reliable partial equilibrium estimates of the effects of bilateral and non-discriminatory trade policies within the same comprehensive, and theoretically-consistent econometric specification. Our recommendations apply equally to analyses with aggregate and disaggregated data. Interpretation, consistent aggregation methods, and data challenges and sources for gravity estimations are discussed as well. Empirical exercises demonstrate the usefulness, validity, and applicability of our methods.
\end{abstract}

JEL-Codes: F130, F140, F160.

Keywords: structural gravity, trade policy, estimation, partial equilibrium analysis.

\author{
Roberta Piermartini \\ Economic Research and Statistics Division \\ World Trade Organization \\ Geneva / Switzerland \\ roberta.piermartini@wto.org
}

\author{
Yoto V. Yotov \\ School of Economics \\ Drexel University \\ USA - Philadelphia, PA 19104 \\ yotov@drexel.edu
}

\section{July 14, 2016}

This manuscript, along with a companion paper titled "General Equilibrium Trade Policy Analysis with Structural Gravity", are written in preparation to contribute to an extension of the "A Practical Guide to Trade Policy Analysis", co-published by the World Trade Organization (WTO) and the United Nations Conference on Trade and Development (UNCTAD). As this is a working paper, it is still subject to changes and we welcome and will try to accommodate any useful comments and suggestions. We are indebted to Delina Agnosteva, Mario Larch, and Thomas Zylkin for their careful reading and excellent comments on earlier versions of this document, and to Michela Esposito for her comments and for her competent research assistance. We thank James Anderson, Richard Barnett, Davin Chor, Gabriel Felbermayr, Russell Hillberry, Lou Jing, Ma Lin, Antonella Liberatore, Andreas Maurer, José-Antonio Monteiro, Jurgen Richtering, Stela Rubinova, Serge Shikher, Costas Syropoulos, Robert Teh, Thomas Verbeet, Mykyta Vesselovsky, and seminar and workshop participants at the ifo Institute, the World Trade Organization, the World Bank, the U.S. International Trade Commission, Global Affairs Canada, the University of Ottawa, and the National University of Singapore for helpful suggestions and discussions. We also benefitted from the suggestions of the participants in the 2015 WTO Thematic Trade Policy Analysis course, and from the feedback of the graduate students who took the Gravity course module at Princeton University and at Drexel University in 2015 and 2016. Yotov thanks the researchers at the Economic Research and Statistics Division of the WTO and at the ifo Institute for their hospitality during his visits in 2014 and 2015, respectively, when parts of this work were completed. The views and opinions expressed in this document are solely those of the authors and do not reflect the official policy or position of any unit of WTO and/or UNCTAD. All errors are our own. 


\section{Contents}

\begin{tabular}{lll}
\hline & Introduction: Motivation and Goals & 3
\end{tabular}

2 Structural Gravity: From Theory to Empirics 4

2.1 Structural Gravity: A Brief Review . . . . . . . . . . . . . . . . . . . . . . 4

2.2 A Traditional Estimating Gravity Equation . . . . . . . . . . . . . . . . . . 5

\begin{tabular}{|lll}
\hline & Estimation: Challenges, Solutions, and Best Practices & 6
\end{tabular}

3.1 Estimation Challenges and Solutions . . . . . . . . . . . . . . . . 6

$3.2 \quad$ Practical Recommendations for Estimating Structural Gravity . . . . . . . . 13

$3.3 \quad$ A Theoretically-consistent Estimating Gravity Model . . . . . . . . . . . . . 15

4 Interpretation and Aggregation of Gravity Estimates 16

4.1 Interpretation of Gravity Estimates . . . . . . . . . . . . . . . . . . . 17

4.2 Consistent Aggregation of Bilateral Trade Costs . . . . . . . . . . . . . . . . 18

5 Gravity Data: Sources and Limitations 20

5.1 Bilateral Trade Flows Data . . . . . . . . . . . . . . . . . . . . . . 20

5.2 Bilateral Trade Costs Data . . . . . . . . . . . . . . . . . . . . 23

5.2 .1 Tariff Data . . . . . . . . . . . . . . . . . . . . . . . . 24

5.2 .2 Data on Non-tariff Measures . . . . . . . . . . . . . . . . . 25

6 Estimating the Effects of Trade Policy: Applications 30

6.1 Traditional Gravity Estimates . . . . . . . . . . . . . . . . . . . . . 31

$6.2 \quad$ A Simple Solution to the 'Distance Puzzle' in Trade . . . . . . . . . . . . . . 34

6.3 Estimating the Effects of Regional Trade Agreements . . . . . . . . . . . . . 38

6.4 Estimating the Effects of Unilateral Trade Policy . . . . . . . . . . . . . . . 41

\begin{tabular}{lll}
\hline 7 & Conclusion & 43
\end{tabular}

\begin{tabular}{ll}
\hline References & 44
\end{tabular}

\begin{tabular}{ll}
\hline Tables and Figures & 50
\end{tabular}

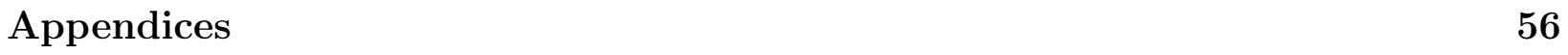




\title{
1 Introduction: Motivation and Goals
}

\author{
"He who loves practice without theory is like the sailor who boards ship without a \\ rudder and compass and never knows where he may cast."
}

Leonardo da Vinci (1452-1519)

Despite solid theoretical foundations ${ }^{1}$ and remarkable empirical success $2^{2}$ the empirical gravity equation is still often applied a-theoretically and without account for important estimation challenges that may lead to biased and even inconsistent gravity estimates. The objective of this manuscript is to serve as a practical guide for estimating the effects of trade policies (and other determinants of bilateral trade) with the structural gravity model. ${ }^{3}$

In order to achieve this goal we rely heavily on the theoretical gravity model and we review and implement the latest developments in the empirical gravity literature. The analysis is developed in several steps:

- We start with a brief review of the theoretical foundations of the Armington-CES gravity model of Anderson (1979). We use the Armington-CES framework as a representative theoretical setting for a wide family of trade models that all lead to the same empirical gravity specification, cf. Anderson (2011) and Costinot and Rodríguez-Clare (2014). Thus, our recommendations and best empirical practices apply to structural gravity estimations in general.

- We present the main challenges with gravity estimations and we review and discuss the solutions that have been proposed in the trade literature to address those challenges.

\footnotetext{
1 Anderson $(1979)$ is the first to offer an economic theory of gravity under the assumptions of constant elasticity of substitution (CES) and product differentiation by place of origin (Armington, 1969). Since then, the gravity model has been derived under many alternative microtheoretic foundations including a Ricardian setting, e.g. Eaton and Kortum (2002), a Heckscher-Ohlin structure, e.g. Bergstrand (1989) and Deardorff (1998), monopolistic competition, e.g. Krugman (1980) and Bergstrand (1985), entry of heterogeneous firms and selection into markets, e.g. Chaney (2008) and Helpman, Melitz and Rubinstein (2008). We refer the reader to Anderson (2011), Arkolakis, Costinot and Rodríguez-Clare (2012), and Costinot and RodríguezClare (2014) for recent reviews of the theoretical foundations of gravity. Larch and Yotov (2016) offer derivations and comparison between the leading gravity frameworks on the demand and on the supply side and discuss methods to perform general equilibrium analysis with the structural gravity model.

${ }^{2}$ The gravity model owes much of its popularity to its unprecedented predictive power. Empirical gravity models traditionally enjoy fit of between 60 and 90 percent with aggregate data as well as with sectoral data for both goods and for services. Head and Mayer (2014) offer representative estimates and evidence for the empirical success of gravity with aggregate data. Anderson and Yotov (2010) present and discuss sectoral gravity estimates with goods trade. Anderson et al. (2015) demonstrate that gravity woks very well with services sectoral data. Finally, Aichele, Felbermayr and Heiland (2014) estimate sectoral gravity for agriculture, mining, manufacturing goods and services.

${ }^{3}$ Our work complements and extends the analysis from two excellent reviews of the developments in the empirical gravity literature including Baldwin and Taglioni (2006), Head and Mayer (2014), and UNCTADWTO (2012). We view the practical nature of our work, the focus on estimating the effects of trade policies, and the synthesis of specific recommendations to address various challenges with the estimation of gravity as distinctive features of this paper.
} 
- We integrate the latest developments in the empirical gravity literature and we formulate six recommendations to obtain reliable partial equilibrium estimates of the effects of bilateral and non-discriminatory trade policies within the same comprehensive, and theoretically-consistent econometric specification. Our six best-practices for structural gravity estimations include: (i) Use panel data: (ii) Allow for ddjustment in trade flows by using interval data instead of consecutive years; (iii) Include intra-national trade flows: (iv) Use directional (exporter and importer) time-varying fixed effects; (v) Employ pair fixed effects; (vi) Estimate gravity in multiplicative form (with the Poisson Pseudo Maximum Likelihood, PPML, estimator). Consistent with gravity theory, our recommendations apply equally to analyses with aggregate and with disaggregated data.

- We discuss the interpretation of the partial equilibrium gravity estimates and we present methods for consistent aggregation of bilateral trade costs.

- We present the data sources for gravity estimations and we discuss various data challenges and limitations.

- We finish with a series of empirical exercises that demonstrate the usefulness, validity, and applicability of our methods. ${ }^{5}$ Specifically, (i) We estimate traditional gravity regressions and discuss the properties of the estimates; (ii) We use the structural gravity model to resolve the 'distance puzzle' in trade and to capture the effects of globalization; (iii) We obtain estimates of regional trade agreements (RTAs), as a representative form of bilateral trade policy, and (iv) We estimate the effects of MFN tariffs, as a representative form of non-discriminatory trade protection policy.

The remainder of the paper is organized as follows. In Section 2 we briefly review the structural gravity equation and we present the corresponding traditional estimating equation. In Section 3, we discuss the main estimation challenges, we review solutions to these challenges and we offer recommendations for theoretical gravity specifications and estimations. Section 4 offers interpretation and aggregation methods. Section 5 discusses data sources and challenges. Several applications are presented in Section 6. Section 7 concludes.

\section{Structural Gravity: From Theory to Empirics}

Under the assumptions that goods are differentiated by place of origin (Armington, 1969) and that consumer preferences are homothetic, identical across countries, and approximated by a CES utility function, Anderson (1979) derives the first theoretical foundations of economic gravity. Anderson and van Wincoop (2003) refine and popularize the ideas of Anderson

\footnotetext{
${ }^{4}$ We also discuss adjustments to our best practices for cross-section gravity estimations.

${ }^{5}$ Stata codes that produce the results from these exercises are available by request from the authors.
} 
(1979) by delivering the following structural gravity system of trade:

$$
\begin{aligned}
X_{i j, t} & =\frac{Y_{i, t} E_{j, t}}{Y_{t}}\left(\frac{t_{i j, t}}{P_{j, t} \Pi_{i, t}}\right)^{1-\sigma}, \\
\Pi_{i, t}^{1-\sigma} & =\sum_{j}\left(\frac{t_{i j, t}}{P_{j, t}}\right)^{1-\sigma} \frac{E_{j, t}}{Y_{t}} \\
P_{j, t}^{1-\sigma} & =\sum_{i}\left(\frac{t_{i j, t}}{\Pi_{i, t}}\right)^{1-\sigma} \frac{Y_{i, t}}{Y_{t}}
\end{aligned}
$$

Here, at each point of time $t, X_{i j, t}$ denotes trade flows from exporter $i$ to destination $j ; E_{j, t}$ is the total expenditure in importer $j ; Y_{i, t}$ is the value of total production in exporter $i$; $Y_{t}$ is the value of world output; $t_{i j, t}$ denotes bilateral trade frictions between partners $i$ and $j ; \sigma>1$ is the elasticity of substitution among goods from different countries; Finally, $P_{j, t}$ and $\Pi_{i, t}$ are structural terms coined by Anderson and van Wincoop (2003) as the inward and the outward multilateral resistances, respectively. The multilateral resistances are the vehicles that translate the initial, partial equilibrium effects of trade policy at the bilateral level to country-specific effects on consumer and producer prices, which naturally can be integrated with models of the labor market, the environment, etc. Larch and Yotov (2016) offer a detailed discussion of the properties of the multilateral resistances and demonstrate their practical uses and importance for GE analysis. Instead, our focus for the rest of the manuscript will be on obtaining sound estimates of bilateral trade costs and the initial trade response of bilateral trade to changes in trade policy. Accordingly, from now on we will focus on the structural gravity equation (1).

Log-linearizing Equation (1) and expanding it with an additive error term, $\epsilon_{i j, t}{ }^{6}$ obtains the following estimating gravity equation:

$$
\ln X_{i j, t}=\ln E_{j, t}+\ln Y_{i, t}-\ln Y_{t}+(1-\sigma) \ln t_{i j, t}-(1-\sigma) \ln P_{j, t}-(1-\sigma) \ln \Pi_{i, t}+\epsilon_{i j, t} .
$$

Specification (4) is the most popular version of the empirical gravity equation, and it has been used routinely in the trade literature to study the effects of various determinants of bilateral trade.7 Despite the numerous applications of the gravity model and despite the great progress in the empirical gravity literature, many of the gravity estimates in the existing literature still suffer biases and even inconsistency, which, as we demonstrate below, can be avoided with some simple steps and stricter adherence to gravity theory.

Before we discuss the main challenges with gravity estimations and present our best practice recommendations, we note that instead of estimating trade costs, some authors calibrate bilateral trade costs by using combinations of ratios of bilateral trade and production data. The idea is to net out all country-specific determinants of bilateral trade in order to isolate

\footnotetext{
${ }^{6}$ We discuss possible caveats with the gravity error term later in this paper.

${ }^{7}$ Hundreds s of papers have used the gravity equation to study the effects of Geography, Demographics, Regional Trade Agreements (RTAs), Tariffs, Exports Subsidies, Embargoes, Trade Sanctions, World Trade Organization membership, Currency Unions, Foreign Aid, Immigration, Foreign Direct Investment, Cultural Ties, Trust, Reputation, Mega Sporting Events (Olympic Games and World Cup), Melting Ice Caps, etc. on international trade.
} 
only the effects of bilateral trade costs (or even their time-varying components). The advantage of the calibration approach is that, by construction, it delivers bilateral trade costs that match the trade data perfectly. One disadvantage is that this approach cannot identify the effects of specific trade policies. Another, related, disadvantage of the calibration approach is that "no way is calibration a substitute for actual econometrics that tests [our] view about how the world works" (Krugman, 2011). In other words, applied to our analysis, a calibration approach would 'assume' an initial impact of trade policy instead of 'test', when data permit, whether a specific trade policy actually resulted in a significant desired impact. For prominent examples of papers that calibrate trade costs, we refer the reader to Head and Ries (2001), Romalis (2007), Novy (2013b), and Caliendo and Parro (2015). Anderson, Larch and Yotov (2015) demonstrate how to combine the estimation and calibration approaches in order to obtain GE effects of trade policy within the structural gravity framework. For the rest of the chapter we focus our attention exclusively on estimating trade costs and the effects of trade policies.

\section{Estimation: Challenges, Solutions, and Best Practices}

We begin this section with a discussion of the main challenges that need to be addressed in order to obtain reliable estimates with the structural gravity model. In addition, we review and discuss the solutions that have been proposed in the literature to address each of those challenges. Then, we capitalize on the latest developments in the gravity literature to formulate and motivate six recommendations for estimations with the gravity model. Finally, we propose a comprehensive and theoretically-consistent estimating gravity specification that simultaneously identifies the effects of bilateral and unilateral non-discriminatory trade policy.

\subsection{Estimation Challenges and Solutions}

- Challenge 1: Multilateral Resistances (MRs). One obvious challenge with the estimation of gravity equation (4) is that the multilateral resistance terms $\left(P_{j, t}\right.$ and $\left.\Pi_{i, t}\right)$ are theoretical constructs and, as such, they are not directly observable by the researcher and/or by the policy maker. Baldwin and Taglioni (2006) emphasize the importance of proper control for the MR terms by characterizing studies that do not do that as committing the 'Gold Medal Mistake'.

Solutions. The treatment of the multilateral resistance terms in gravity estimations has evolved over the years and researchers have proposed various solutions to this challenge. In their original paper, Anderson and van Wincoop (2003) use iterative custom programming to account for the multilateral resistances in a static setting.

Many researchers have used a reduced-form version of the custom treatment from Anderson and van Wincoop (2003), where the MR terms are approximated by the so-called 'remoteness indexes' that are constructed as weighted averages of bilateral distance, with Gross Domestic Products (GDPs) used as weights. See for example Wei (1996) and Baier and Bergstrand (2009). Head and Mayer (2014) criticize such reduced- 
form approaches as they "bear little resemblance to [their] theoretical counterpart." (p. 150).

A third alternative approach to handle the multilateral resistances is to simply eliminate these terms by using appropriate ratios based on the structural gravity equation. Notable examples include Head and Ries (2001), Head, Mayer and Ries (2010), and Novy (2013a).

Finally, in order to overcome the computational difficulties of the custom programming from Anderson and van Wincoop (2003), while at the same time fully accounting for the MR terms, Hummels (2001) and Feenstra (2004) advocate the use of directional (exporter and importer) fixed effects in cross-section estimations. More recently, Olivero and Yotov (2012) extend the cross-section recommendations from Hummels (2001) and Feenstra (2004) and demonstrate that the MR terms should be accounted for by exporter-time and importer-time fixed effects in a dynamic gravity estimation frameworks with panel data 8

- Challenge 2: Zero Trade Flows. Starting with Tinbergen (1962) and continuing today, the OLS estimator has been the most widely used technique to estimate various versions of gravity equation (4). A clear drawback of the OLS approach, however, is that it cannot take into account the information contained in the zero trade flows, because these observations are simply dropped from the estimation sample when the value of trade is transformed into a logarithmic form. The problem with the zeroes becomes more pronounced the more disaggregated the trade data are, and it is especially severe for sectoral services trade (due to the highly localized consumption and highly specialized production).

Solutions. Over the years, researchers have proposed several approaches to handle the presence of zero trade flows. One frequently applied and very convenient (but theoretically inconsistent!!) method is to just add a very small, and in fact completely arbitrary, value to replace the zero trade flows. As noted in Head and Mayer (2014), however, this approach should be avoided because the results depend on the units of measurement [and] the interpretation of the [gravity] coefficients as elasticities is lost ${ }^{9}$ Eaton and Tamura (1995) and Martin and Pham (2008) propose the use of Tobit estimators as an econometric solution to the presence of zeroes. However, this causes a disconnect between estimation and theory, which is silent about the determination of

\footnotetext{
${ }^{8}$ It should be noted that in addition to accounting for the unobservable multilateral resistance terms, the exporter-time and importer-time fixed effects will also absorb the size variables $\left(E_{j, t}\right.$ and $\left.Y_{i, t}\right)$ from the structural gravity model as well as all other observable and unobservable country-specific characteristics which vary across these dimensions, including various national policies, institutions, exchange rates, etc. Anderson, Larch and Yotov (2015) and Larch and Yotov (2016) offer further discussion on the relationship between the gravity fixed effects and their structural counterparts and demonstrate how this relationship can be used to perform GE analysis in Stata.

${ }^{9}$ In principle, the interpretation problem can be fixed by using the inverse hyperbolic sine function, http://www.stata.com/statalist/archive/2005-03/msg01010.html. However, this procedure has to be applied with caution because it is a non-linear transformation (as is the log-transformation), which means that with heteroskedastic trade data one may end up with inconsistent estimates, cf. Santos Silva and Tenreyro (2006).
} 
the Tobit thresholds. The Tobit model would apply to a situation where small values of trade are rounded to zero or actual zero trade might reflect desired negative trade. 10 This difficulty is overcome by Helpman, Melitz and Rubinstein (2008) who propose a theoretically-founded two-step selection process, where exporters must absorb some fixed costs to enter a market. Thus, fixed costs provide an intuitive economic explanation for the zero trade flows to bridge theory and empirics. The HMR model is estimated in two stages including a first-stage probit estimation, which determines the probability to export, and a second-stage OLS estimation based on the positive sample of trade flows that also accounts for selection into exporting. Some challenges with the HMR estimation are that it is hard to find good exclusion restrictions for the first-stage probit estimation and/or the need for custom programming when identification relies on functional form. Additional difficulties with the HMR approach arise for panel data estimations and when dynamic considerations are taken into account.

Finally, an easy and convenient solution to the presence of zero trade flows is to estimate the gravity model in multiplicative form. This approach is advocated by Santos Silva and Tenreyro (2006) who propose the use of the Poisson Pseudo Maximum Likelihood estimator for gravity estimations 11 Santos Silva and Tenreyro (2011) use Monte Carlo simulations to show that PPML performs very well even when the proportion of zeroes is large. Next, we discuss an additional advantage of the PPML estimator, which, we believe, makes this technique particularly appropriate for gravity estimations.

- Challenge 3: Heteroskedasticity of Trade Data. It is well known that trade data are plagued by heteroskedasticity. The problem is important because, as pointed out by Santos Silva and Tenreyro (2006), in the presence of heteroskedasticity (and owing to Jensen's inequality), the estimates of the effects of trade costs and trade policy are not only biased but also inconsistent when gravity is estimated in log-linear form with the OLS estimator (or any other estimator that requires non-linear transformation).

Solutions. We discuss two possible solutions to address the issue of heteroskedasticity in the gravity equation. One approach is to estimate (4) after transforming the dependent variable into size-adjusted trade, which is defined as the ratio between trade and the product of the sizes of the two markets, $X_{i j, t} /\left(E_{j, t} Y_{i, t}\right)$, cf. Anderson and van Wincoop (2003). The intuition behind this adjustment is that, arguably, the variance of the error term $\epsilon_{i j, t}$ is proportional to the product of the sizes of the two markets. A potential drawback of this approach is that it accounts for (the product of) country size as the only source for the problem of heteroskedasticity. Furthermore, using the proposed size-adjusted trade as dependent variable would not eliminate the 'zero trade flows challenge' that we presented earlier.

An alternative and more comprehensive approach, due to Santos Silva and Tenreyro

\footnotetext{
${ }^{10}$ See UNCTAD-WTO (2012) Chapter 3 for a more detailed discussion.

${ }^{11}$ The estimation can be performed by several Stata commands including poisson, glm, and ppml. We recommend the latter command. For a discussion of the relative merits of the PPML estimator vs. other linear and non-linear estimators, we refer the reader to Santos Silva and Tenreyro (2006), Santos Silva and Tenreyro (2011), Egger and Staub (2014), and Head and Mayer (2014).
} 
(2006), is to employ the PPML estimator ${ }^{12}$ Combined with the fact that, as discussed above, PPML also effectively handles the presence of zero trade flows, makes this estimator a very attractive choice for empirical gravity analysis. In Section 3.2 we also discuss one more property of PPML, which makes it particularly suitable for general equilibrium analysis with the structural gravity model.

- Challenge 4: Bilateral Trade Costs. Proper specification of bilateral trade costs is crucial for partial equilibrium as well as for general equilibrium trade policy analysis.

Solutions. The standard practice in the literature to proxy for the bilateral trade cost term, $(1-\sigma) \ln t_{i j, t}$, from specification (4) is to use a series of observable variables most of which have become standard covariates in empirical gravity specifications: 13

$$
(1-\sigma) \ln t_{i j, t}=\beta_{1} \ln D I S T_{i j}+\beta_{2} C N T G_{i j}+\beta_{3} L A N G_{i j}+\beta_{4} C L N Y_{i j}+\beta_{5} R T A_{i j, t}+\beta_{6} \tau_{i j, t} .
$$

The first two variables in Equation (5) are the most widely used and robust gravity proxies for trade costs. $\ln D I S T_{i j}$ is the logarithm of bilateral distance between trading partners $i$ and $j$, and $C N T G_{i j}$ is an indicator variable that captures the presence of contiguous borders ${ }^{14} L A N G_{i j}$ and $C L N Y_{i j}$ are dummy variables that take a value of one for common official language and for the presence of colonial ties, respectively. Finally, $R T A_{i j, t}$ and $\tau_{i j, t}$ are trade policy variables. $R T A_{i j, t}$ is a dummy variable that accounts for the presence of a regional trade agreement between trading partners $i$ and j. $R T A_{i j, t}$ takes a value of one when two countries are members of the same RTA, and it is equal to zero otherwise. $\tau_{i j, t}$ accounts for bilateral tariffs and is defined as $\tau_{i j, t}=\ln \left(1+\right.$ tarif $\left.f_{i j, t}\right)$, where tarif $f_{i j, t}$ is the tariff that country $j$ imposes on imports from country $i$. Importantly, since tariffs act as direct price shifters, the coefficient on $\tau_{i j, t}$ can be expressed only in terms of the trade elasticity of substitution $\beta_{6}=-\sigma$, which means that the trade elasticity itself can be recovered directly from the estimate on $\tau_{i j, t}$ as $\hat{\sigma}=-\hat{\beta}_{6} \cdot{ }^{15}$ We demonstrate that with an application in Section 6 .

An important consideration in estimating the effects of the trade policy variables, e.g. $R T A_{i j, t}$ and $\tau_{i j, t}$, is that they are endogenous. Additional challenges with the bilateral tariff variable are posed by data availability and by the fact that many countries apply MFN tariffs, which are country-specific by definition. We address these challenges in turn next.

- Challenge 5: Endogeneity of Trade Policy. One of the biggest challenges in obtaining reliable estimates of the effects of trade policy within the gravity model is that the trade policy variables are endogenous., e.g. it is possible that trade policy may be correlated with unobservable cross-sectional trade costs. 'Reverse causality',

\footnotetext{
${ }^{12}$ In principle, the heteroskedasticity issue can be addressed with other estimators, e.g. the Gamma estimator, that estimate gravity in multiplicative form.

${ }^{13}$ See Anderson and van Wincoop (2004) for a thorough survey and an informative discussion of trade costs. Head and Mayer (2014) offer a comprehensive discussion of the estimates of the standard gravity covariates.

${ }^{14}$ We refer the reader to Disdier and Head (2008) and Head and Mayer (2013) for excellent analysis of the use and impact of distance in gravity regressions.

${ }^{15}$ See Appendix A for derivation and implications of the structural gravity model with tariffs.
} 
i.e. the possibility that, all else equal, it is more likely to liberalize trade with a country that is already a significant trade partner, is a prominent example.

Solutions. The issue of endogeneity of trade policy is well-known in the trade literature, cf. Trefler (1993). However, primarily due to the lack of reliable instruments, early attempts to account for endogeneity with standard instrumental variable (IV) treatments in cross-sectional settings have not been successful in addressing the problem. 16

Baier and Bergstrand (2007) summarize the findings from existing IV studies as "at best mixed evidence of isolating the effect of free trade agreements (FTAs) on trade flows." The same authors propose the use of the average treatment effect (ATE) methods described in Wooldridge $(2010)$ to treat the endogeneity of free trade agreements. In particular, Baier and Bergstrand (2007) advocate the use of country-pair fixed effects or first-differencing in order to account for or to eliminate, respectively, the unobservable linkages between the endogenous free trade agreement covariate and the error term in gravity regressions. ${ }^{17}$ Given the crucial role of bilateral trade costs for general equilibrium analysis, we recommend the use of pair fixed effects. It should be noted, of course, that the set of pair fixed effects will absorb all bilateral time-invariant covariates, e.g. bilateral distance, that are used standardly in gravity regressions. However, the pair fixed effects will not prevent the estimation of the effects of bilateral trade policy, since trade policies are time-varying by definition. Combined with the additional advantages that the pair fixed effects will also account for any unobservable time invariant trade cost components 18 and also successfully account for endogeneity of trade policy, makes the use of pair dummies our preferred choice to flexibly measure bilateral trade costs in gravity equations.

- Challenge 6: Non-discriminatory Trade Policy. Unilateral and non-discriminatory trade policies, such as export subsidies or most-favored-nation (MFN) tariffs play prominent roles in the current trade policy landscape. Despite the importance of these policies and the natural interest to gauge their effects on bilateral trade flows, researchers and policy makers have struggled to estimate the effects of non-discriminatory trade policy within the structural gravity model. The issue with non-discriminatory trade policy covariates, such as subsidies and various export promotion measures on the exporter side and MFN tariffs or trade facilitation policies on the importer side, is that these variables are exporter- and/or importer-specific, respectively, and therefore they will be absorbed by the exporter-time and by the importer-time fixed effects that need to be used in order to control for the multilateral resistances in the structural gravity model. Head and Mayer (2014) summarize this challenge well: "In the presence of importer and exporter fixed effects a variety of potentially interesting trade determinants can no longer be identified in a gravity equation. Notably, (1) anything

\footnotetext{
${ }^{16}$ See for example Magee (2003) and Baier and Bergstrand 2002, 2004). Egger et al. (2011) offer a recent IV treatment of the endogeneity of trade agreements in a cross-section setting.

${ }^{17}$ The use of the ATE method requires panel trade data, which has become more widely available and increasingly reliable over time.

${ }^{18}$ In fact, Egger and Nigai (2015) and Agnosteva, Anderson and Yotov (2014) demonstrate that the pairfixed effects are a better measure of bilateral trade costs as compared to the standard set of gravity variables.
} 
that affects exporters propensity to export to all destinations (such has having hosted the Olympics or being an island), (2) variables that affect imports without regard to origin, such as country-level average applied tariff, (3) sums, averages, and differences of country-specific variables." (p. 158).

Solutions. One possible solution is not to use fixed effects for the MR terms but instead approximate them with the 'remoteness' indexes that we discussed earlier. This will allow separate identification of the effects of the country-specific policies of interest. However, we do not recommend this approach because it does not account properly for the multilateral resistance terms, which results in biased gravity estimates (including the effects of trade policy), as forcefully argued by Anderson and van Wincoop (2003).

Another solution is to employ a two-stage estimation, where the estimates of the multilateral resistances from the first-stage gravity regression are explained in an auxiliary regression that includes the non-discriminatory covariate of interest. See Anderson and Yotov (2016) and Head and Mayer (2014) for examples and discussion of this approach.

Finally, Heid, Larch and Yotov (2015) propose a simple solution that allows for identification of the effects of unilateral and non-discriminatory effects of trade policy in a specification that is perfectly consistent with the structural gravity model. Specifically, Heid, Larch and Yotov (2015) recognize and capitalize on the fact that while non-discriminatory trade policies are indeed country-specific, they do not apply to intra-national trade. At the same time, the structural gravity model applies simultaneously for intra-national and for international trade flows. Thus, the simple adjustment to the estimation of structural gravity that is proposed by Heid, Larch and Yotov (2015) is to estimate the model with international and with intra-national trade flows, in which case identification of non-discriminatory trade policies is possible since, in effect, the non-discriminatory variables become bilateral in nature. $\sqrt{19}$ We demonstrate this argument with an application to MFN tariffs in Section $6{ }^{20}$

- Challenge 7: Adjustment to Trade Policy Changes. It is natural to expect that the adjustment of trade flows in response to trade policy changes will not be instantaneous. Accordingly, Trefler (2004) criticizes trade estimations pooled over consecutive years. The challenge of adjustment is even more pronounced in econometric specifications with fixed effects such as the ones described here. As noted in Cheng and Wall (2005) "[f]ixed-effects estimation is sometimes criticized when applied to data pooled over consecutive years on the grounds that dependent and independent variables

\footnotetext{
${ }^{19}$ Yotov (2012) also capitalizes on the theoretically consistent inclusion of intra-national trade flows in gravity estimations in order to resolve the 'distance puzzle' in international trade. The idea is that when international trade costs, and their evolution over time, are measured relative to intra-national trade costs, the puzzling persistence of the effects of distance on trade disappear. Bergstrand, Larch and Yotov (2015) extend the idea to resolve the 'missing globalization' puzzle in international trade.

${ }^{20}$ As noted by Heid, Larch and Yotov (2015), the estimates of non-discriminatory trade policies in the structural gravity model are less likely to be subject to endogeneity concerns as compared to their bilateral counterparts for two reasons. First, it is unlikely that a non-discriminatory trade policy will be influenced by any bilateral trade flow. Second, the directional fixed effects in the structural gravity model will absorb much of the unobserved correlation between the non-discriminatory trade policy covariates and the gravity error term.
} 
cannot fully adjust in a single year's time." (Footnote 8, p. 52).

Solutions. In order to avoid this critique, researchers have used panel data with intervals instead of data pooled over consecutive years. For example, Trefler (2004) uses 3-year intervals, Anderson and Yotov (2011) use 4-year intervals, and Baier and Bergstrand (2007) use 5-year intervals. Olivero and Yotov (2012) provide empirical evidence that gravity estimates obtained with 3-year and 5-year interval trade data are very similar, however, they also confirm that estimations that are performed with panel samples pooled over consecutive years produce suspicious estimates of the trade cost elasticity parameters.

- Challenge 8: Gravity with Disaggregated Data. Many trade policies are negotiated and applied at the sectoral level, e.g. tariffs. While it is in principle possible to aggregate trade policy and still use the aggregate gravity model, such aggregation practices should be avoided and, whenever possible, gravity should be estimated at the level of aggregation which is the target of the specific policy. Furthermore, even for policies that are negotiated at the aggregate level, e.g. some regional trade trade agreements, it may be desirable to also obtain sectoral effects because the effects of these non-discriminatory policies may actually be quite heterogenous across sectors. These examples point to the need for proper gravity estimations at the sectoral level.

Solutions. Fortunately, one of the most attractive properties of the Armington-CES gravity theory is that the model is separable, i.e. both at the aggregate and at the sectoral level bilateral expenditures across countries are separable from output and expenditure at the country level. ${ }^{21}$ As demonstrated by Anderson and van Wincoop (2004), one nice implication of separability is that for a given set of country-level output $\left(Y_{i, t}^{k}\right)$ and expenditure $\left(E_{j, t}^{k}\right)$ values, where $k$ denotes a class of goods/sector, theory delivers the familiar sectoral gravity equation:

$$
X_{i j, t}^{k}=\frac{Y_{i, t}^{k} E_{j, t}^{k}}{Y_{t}^{k}}\left(\frac{t_{i j, t}^{k}}{P_{j, t}^{k} \Pi_{i, t}^{k}}\right)^{1-\sigma_{k}}
$$

Two properties of equation (6) deserve a note. First, by definition, the bilateral trade $\operatorname{costs} t_{i j, t}^{k}$, including the effects of trade policy, are sector-specific. Second, the multilateral resistances are sector-specific as well. From an empirical perspective, trade separability implies that (6) can be estimated for each sector as if the data were aggregate. Alternatively, gravity can be estimated with data pooled across sectors, in which case the proper treatment of the multilateral resistance requires exporter-product-time and importer-product-time fixed effects, and the effects of trade policy should be allowed to vary by sector. Depending on the question of interest, the estimates of the trade policy variables in gravity estimations that are pooled across sectors can be sector-specific or constrained to be common across sectors.

\footnotetext{
${ }^{21}$ Larch and Yotov (2016) derive and demonstrate the equivalence between the sectoral structural gravity systems on the demand side, a la Anderson and van Wincoop (2003), and on the supply side, a la Eaton and Kortum (2002). Thus, demonstrating that 'separability' is a general property of the structural gravity model, which does not apply only to the Armington-CES framework.
} 


\subsection{Practical Recommendations for Estimating Structural Gravity}

Taking into account all of the above considerations and combining what we believe are the best solutions to address the challenges with the estimation of gravity, we recommend (and motivate) the following best practices for estimating structural gravity equations:

- Recommendation 1: Use Panel Data. Whenever available, panel data should be used to obtain structural gravity estimates.

Motivation and Caveats. The main reasons for this recommendation include: The fact that the use of panel data will lead to improved estimation efficiency; In addition, the panel dimension would enable researchers to apply the pair-fixed-effects methods of Baier and Bergstrand (2007) to address the issue of endogeneity of trade agreements; Third, on a related note, the use of panel data would allow for a flexible and comprehensive treatment and estimation of the effects of time-invariant bilateral trade costs with pair fixed effects. The downside is that panel data may not always be available. When panel data are not available and gravity estimations are performed on crosssection samples, best practices 3,4 , and 6 from our list continue to hold, however, steps 2 and 5 below are no longer applicable. In that case, we recommend the use of the standard set of gravity variables (e.g., bilateral distance, etc.), instead of pair fixed effects, to proxy for bilateral trade costs. However, following Egger and Nigai (2015) and Agnosteva, Anderson and Yotov (2014), we call for caution with the interpretation of the error term, which may capture the systematic effects of unobserved trade costs. In order to address the endogeneity of bilateral trade policy, we recommend IV treatment and we refer the reader to Baier and Bergstrand (2004) and Egger et al. (2011).

- Recommendation 2: Allow for Adjustment in Trade Flows. Researchers should use panel data with intervals instead of data pooled over consecutive years.

Motivation and Caveats. Interval panel data should be employed in order to allow for adjustment in bilateral trade flows in response to trade policy or other changes in trade costs and to address the critique from Cheng and Wall (2005). Olivero and Yotov (2012) build a dynamic gravity model and experiment with alternative interval specifications and find that gravity estimates obtained with 3-, 4-, and 5-year lags deliver similar results with respect to the estimates of the standard gravity variables. Our recommendation is to experiment with alternative intervals while keeping estimation efficiency in mind.

- Recommendation 3: Include Intra-national Trade Flows. Gravity estimations should be performed with intra-national and international trade data.

Motivation and Caveats. The use of intra-national trade data in structural gravity estimations is desirable for several reasons. First, this will ensure consistency with gravity theory, where consumers choose among and consume domestic as well as foreign varieties. Second, the inclusion of intra-national trade flows leads theoretically consistent identification of the effects of bilateral trade policies. Capitalizing on that, Dai, Yotov and Zylkin (2014) demonstrate that the FTAs from the 90s lead to significant 
trade-diversion effects with respect to intra-national trade. Third, as demonstrated by Heid, Larch and Yotov (2015), the use of intra-national trade flows allows for identification of the effects of non-discriminatory trade policies. Fourth, Yotov (2012) uses intra-national trade flows to demonstrate that the 'distance puzzle' in trade disappears when the effects of distance on international trade are measured relative to the effects of distance on internal trade. Finally, Bergstrand, Larch and Yotov (2015) employ internal and international trade flows to capture the effects of globalization on international trade and to correct for biases in the effects of regional trade agreements. An important feature of the data in all of the above-mentioned studies is that intranational trade is constructed consistently as the difference between gross production value data and total exports. We offer further discussion on the construction and sources of intra-national trade data in the Data Section 5.

- Recommendation 4: Use Directional Time-varying Fixed Effects. In accordance with gravity theory, we recommend the use of directional time-varying (importertime and exporter-time) fixed effects.

Motivation and Caveats. Our recommendation to use exporter-time and importertime fixed effects is motivated by the famous work of Anderson and van Wincoop (2003). Specifically, the directional fixed effects will control for the unobservable multilateral resistances, and potentially for any other observable and unobservable characteristics that vary over time for each exporter and for each importer. In addition, as demonstrated in Anderson, Larch and Yotov (2015) and in Larch and Yotov (2016) the estimates of the fixed effects can be used directly to recover estimates of the general equilibrium (GE) effects of trade policy changes as well as to construct a series of useful GE indexes that summarize and aggregate consistently the effects of trade policy and trade costs.

- Recommendation 5: Employ Pair Fixed Effects. We recommend the use of pair fixed effects.

Motivation and Caveats. We see two major benefits of using pair fixed effects. First, as demonstrated by Baier and Bergstrand (2007), one attractive feature of the pair fixed effects is that they can be used to account for endogeneity of regional trade agreements. Second, on a related note, another attractive feature of the pair fixed effects in gravity estimations is that they provide a flexible and comprehensive account of the effects of all time-invariant bilateral trade costs. Egger and Nigai (2015) and Agnosteva, Anderson and Yotov (2014) demonstrate that the pair fixed effects carry systematic information about trade costs in addition to the information captured by the standard gravity variables. The downside of the use of pair fixed effects is that one cannot identify the effects of any time-invariant bilateral determinants of trade flows, because the latter will be absorbed by the bilateral fixed effects. Agnosteva, Anderson and Yotov (2014) address this issue and propose a two-stage procedure, where the estimates of the pair fixed effects from the first-stage gravity equation are regressed on standard gravity variables in a second-stage estimation. Anderson and Yotov (2016) apply these methods to recover estimates of the pair fixed effects that cannot be identified directly in the first stage, due to missing or zero trade flows, and 
then use the complete set of pair fixed effects to construct the full matrix of bilateral trade costs and to perform counterfactual experiments.

- Recommendation 6: Estimate Gravity with PPML. We favor the use of the PPML estimator for structural gravity estimations.

Motivation and Caveats. We recommend the use of the PPML estimator for the following reasons. First, as demonstrated by Santos Silva and Tenreyro (2006), because gravity is estimated in multiplicative form the PPML estimator accounts for heteroskedasticity, which often plagues trade data. In addition, for the same reason, PPML takes advantage of the information contained in the zero trade flows. Third, Arvis and Shepherd (2013) and Fally (2015) show an additive property of PPML, which ensures that the gravity fixed effects are identical to their corresponding structural terms. Finally, Anderson, Larch and Yotov (2015) demonstrate how the PPML estimator can be used to estimate theory consistent GE effects ${ }^{22}$ Head and Mayer (2014) recommend, as a robustness check, to complement the PPML estimates with those from the Gamma Pseudo Maximum Likelihood (GPML) and with those from Ordinary Least Squares (OLS) 23

\subsection{A Theoretically-consistent Estimating Gravity Model}

Our best practices and recommendations are reflected in the following generic and comprehensive econometric version of the structural gravity model, which can be modified and adjusted by researchers and policy makers depending on their specific needs:

$X_{i j, t}=\exp \left[\pi_{i, t}+\chi_{j, t}+\mu_{i j}+\eta_{1} B T P_{i j, t}+\eta_{2} N E S_{i, t} \times I N T L_{i j}+\eta_{3} N I P_{j, t} \times I N T L_{i j}\right]+\epsilon_{i j, t}$.

Here, $X_{i j, t}$ denotes nominal trade flows, which include international and intra-national trade, at non-consecutive years $t . \pi_{i, t}$ denotes the set of time-varying source-country dummies, which control for the outward multilateral resistances, countries' output shares and, potentially any other observable and unobservable exporter-specific factors that may influence bilateral trade. $\chi_{j, t}$ encompasses the set of time-varying destination-country dummy variables that account for the inward multilateral resistances, total expenditure, and any other observable and unobservable importer-specific characteristics that may influence trade.

$\mu_{i j}$ denotes the set of country-pair fixed effects that serve two main purposes. First, the pair fixed effects are the most flexible and comprehensive measure of time-invariant bilateral trade costs because the former will absorb all time-invariant gravity covariates from (5) along with any other time-invariant bilateral determinants of trade costs that are not observable by the researcher and/or the policy maker. Second, the pair fixed effects will absorb most of

\footnotetext{
${ }^{22}$ See Larch and Yotov (2016) for a detailed discussion and applications related to the last two points.

${ }^{23}$ The main issue that Head and Mayer (2014) find in their simulations is that PPML underestimates the distance effect in their Monte Carlo simulations. However, when the sample size increases, it converges to the true value. We refer the reader to the 'Log of Gravity' web page at http://personal.lse.ac.uk/tenreyro/LGW.html for a series of discussions on the benefits and potential downside of using PPML.
} 
the linkages between the endogenous trade policy variables and the remainder error term $\epsilon_{i j, t}$ in order to control for potential endogeneity of the former. In principle, it is possible that the error term in gravity equations may carry some systematic information about trade costs. However, due to the rich fixed effects structure in specification (7), researchers should be more confident to treat and interpret $\epsilon_{i j, t}$ as a true measurement error. This emphasizes the advantage of using panel data, which allow for the inclusion of pair fixed effects ${ }^{24}$ Finally, we note that whether the error term in 7 is introduced as additive or multiplicative does not matter for PPML25

Turning to the other covariates from specification (7). We use $B T P_{i j, t}$ to denote the vector of any time-varying bilateral determinants of trade flows. Possible candidates here include regional trade agreements, bilateral tariffs, currency unions, etc. In principle, the $B T P_{i j, t}$ vector may include any time-varying covariates, however, given our focus on trade policy we use $B T P$ as an acronym for Bilateral Trade Policy. The next covariate, $N E S_{i, t} \times I N T L_{i j}$, is constructed as the product between two variables: $N E S_{i, t}$, which denotes the vector of any Non-discriminatory Export Support (NES) policies, e.g. export subsidies, and $I N T L_{i j}$, which is a dummy variable that takes a value of one for international trade and it is equal to zero otherwise. Importantly, as emphasized by Heid, Larch and Yotov (2015), the interaction between the country-specific NES variables and the bilateral dummy for international trade flows results in a new bilateral term, i.e. $N E S_{i, t} \times I N T L_{i j}$, which will enable us to identify the effects of any non-discriminatory export support policies, even in the presence of exportertime fixed effects as required by gravity theory. We also note that with appropriate data on export support measures that act as direct price-shifters, the estimate on $N E S_{i, t} \times I N T L_{i j}$ can be used to recover an estimate of the export supply elasticity, which plays a prominent role in theoretical trade policy analysis but has attracted little attention in the empirical trade literature. Finally, $N I P_{j, t} \times I N T L_{i j}$ is constructed as the product between $N I P_{i, t}$, which denotes the vector of any Non-discriminatory Import Protection (NIP) policies and measures, e.g. MFN tariffs, and $I N T L_{i j}$. Similar to $N E S_{i, t} \times I N T L_{i j}$, the term $N I P_{j, t} \times I N T L_{i j}$ is bilateral by construction, which will enable us to identify the effects of any non-discriminatory import protection policies. We demonstrate this with an application in Section 6.

\section{Interpretation and Aggregation of Gravity Estimates}

This section discusses possible approaches to interpret gravity estimates. We also capitalize on the structural properties of the gravity model to demonstrate how gravity estimates can be translated into tariff equivalent effects. Finally, we present theoretically-consistent methods for aggregation of bilateral trade costs and we offer practical recommendations for their implementation.

\footnotetext{
${ }^{24}$ Researchers should be careful with the interpretation of the error terms in cross-section gravity specifications. Recent studies, e.g. Egger and Nigai (2015) and Agnosteva, Anderson and Yotov (2014), demonstrate that the error in cross section gravity regressions indeed carries some systematic information about trade costs. Thus, it may be appropriate to take such effects into account in the construction of bilateral trade costs and carry them over to the general equilibrium analysis. Anderson, Larch and Yotov (2015) demonstrate how this can be done in a simple procedure with the help of the PPML estimator.

${ }^{25}$ For further discussion see the page 644 of Santos Silva and Tenreyro (2006).
} 


\subsection{Interpretation of Gravity Estimates}

There are two widely used (and related) methods to interpret the estimates from gravity regressions. The first approach is to use the gravity estimates to construct trade volume effects. The second approach capitalizes on the theoretical foundations of gravity to convert the estimates of various trade policies and other determinants of trade flows into tariff equivalent effects. In order to demonstrate how the structural gravity estimates can be translated into trade volume effects and interpreted as tariff equivalent effects, we use a simplified version of the empirical gravity model (7):

$$
X_{i j, t}=\exp \left[\beta_{D I S T} \ln D I S T_{i j}+\beta_{R T A} R T A_{i j, t}+\beta_{T A R I F F} \tau_{i j, t}+\pi_{i, t}+\chi_{j, t}\right]+\epsilon_{i j, t} .
$$

Here, $\ln D I S T_{i j}$ is the logarithm of bilateral distance and this covariate will be used as a representative continuous variable in gravity regressions. $R T A_{i j, t}$ is an indicator variable that captures the presence of regional trade agreements. $R T A_{i j, t}$ is equal to one if there is a regional trade agreement between countries $i$ and $j$ at time $t$, and it is equal to zero otherwise. This variable will be used as a representative dummy covariate. Finally, $\tau_{i j, t}=$ $\ln \left(1+\operatorname{tarif} f_{i j, t}\right)$ accounts for bilateral tariffs, where $\operatorname{tarif} f_{i j, t}$ is the ad-valorem tariff, that country $j$ imposes on imports from country $i$ at time $t$. Importantly, as emphasized earlier, the structural interpretation of the coefficient on $\tau_{i j, t}$ is only in terms of the trade elasticity of substitution $\beta_{T A R I F F}=-\sigma{ }^{26}$ We will capitalize on this property in order to construct tariff equivalent effects.

- Trade Volume Effects. The construction of trade volume effects from gravity estimates is straightforward. In the case of continuous variables, such as distance, the interpretation of the estimate of the coefficient on the logarithm of bilateral distance is simply as the elasticity of (the value of trade flows) with respect to distance. For example, the standard value for the distance estimate in gravity regressions $\hat{\beta}_{\text {dist }}=-1$ (Disdier and Head (2008) and Head and Mayer (2014)) implies that a 10\% increase in distance should be accompanied by a $10 \%$ decrease in trade flows.

The volume effects triggered by a change in an indicator gravity variable, e.g. the presence of regional trade agreements, etc., can be calculated in percentage terms as follows:

$$
\left[e^{\hat{\beta}_{\text {dummy }}}-1\right] \times 100,
$$

where $\hat{\beta}_{\text {dummy }}$ is the estimate of the effects of any indicator gravity variable. For example, let's consider the benchmark estimate of the effects of RTAs from Baier and Bergstrand (2007). Their estimate $\hat{\beta}_{R T A}=0.76$ implies the RTAs that entered into force between 1960 and 2000 on average have increased trade by $114 \%,\left[e^{0.76}-1\right] \times 100$.

\footnotetext{
${ }^{26}$ We remind threader that the interpretation of the coefficient on tariffs in gravity regressions depends on the trade flows data used in the estimation. Specifically, the current interpretation assumes trade flows at delivered prices. We refer the reader to Appendix A of this paper for a derivation of a structural gravity model with tariffs.
} 
It should be noted that the estimates of most gravity covariate, with the exception of the direct price shifters (e.g. tariffs), consist of two components: a structural component and a trade cost component. For example, the structural interpretation of the estimate of the coefficient of distance is $\hat{\beta}_{1}=(1-\hat{\sigma}) \times \hat{\beta}_{D I S T}$. This decomposition is useful for two reasons. First, because one can recover the direct effects of distance $\hat{\beta}_{D I S T}=\hat{\beta}_{1} /(1-\hat{\sigma})$. Head and Mayer $(2013)$ perform such analysis to demonstrate that distance variable in gravity estimations accounts for much more than just transportation costs. Second, because it can be used to convert gravity estimates into tariff equivalent effects. We demonstrate next. The exception is the coefficient on direct price-shifters, e.g. tariffs, where, as noted earlier, the coefficient is only a function of the elasticity of substitution.

- Tariff Equivalent Effects. Quantifying the effects of tariffs is easier and useful both from a policy and from a pedagogical perspective. However, the proliferation of non-tariff trade measures poses big challenges in quantifying the effects such policies. Furthermore, often it is useful and desirable to be able to express the effects of alternative trade policies in a consistent measure. The gravity model offers a solution that enables researchers and policy makers to translate the effects of any trade policy variable into a tariff equivalent effect:

$$
\left[e^{\hat{\beta}_{R T A} / \hat{\beta}_{T A R I F F}}-1\right] \times 100,
$$

where $\hat{\beta}_{R T A}$ and $\hat{\beta}_{\text {TARIFF }}$ are the estimates of the effects of RTAs and tariffs, respectively, from Equation (8).

Ideally, one would be able to obtain estimates of the effects of tariffs and all other determinants of trade within the same theoretically-consistent empirical specification. However, as discussed earlier, most gravity estimations do not include tariffs. This does not necessarily preclude the calculation of tariff equivalent effects and one can rely on the structural properties of the gravity model in order to construct them. Capitalizing on the structural interpretation of the coefficient on tariffs as $\beta_{\text {TARIFF }}=-\sigma$, where sigma is the trade elasticity of substitution, equation (10) becomes:

$$
\left[e^{\hat{\beta}_{R T A} /(-\hat{\sigma})}-1\right] \times 100 .
$$

An advantage of the structural specification (11) is that it demonstrates that, in principle, no data on tariffs is needed in order to obtain tariff equivalent effects of other gravity covariates as long as reliable estimates of the trade elasticity of substitution are available from outside studies. Returning to our example of the effects of RTAs from Baier and Bergstrand (2007), and taking a representative value for the elasticity of substitution from the literature, $\sigma=5$, we can infer that the average tariff-equivalent fall of the introduction of RTAs in their sample is a $14.1 \%$, obtained as $\left[e^{0.76 /(-5)}-1\right] \times 100$.

\subsection{Consistent Aggregation of Bilateral Trade Costs}

Aggregation of bilateral trade costs may be desirable for many policy purposes. For example, policy makers in the European Union (EU) may wish to aggregate the effects of changes in 
bilateral trade costs of members to the EU level. Similarly Canadian decision makers may wish to aggregate interprovincial trade costs to the national level. Finally, national agencies may find it useful to consistently aggregate sectoral trade costs to the aggregate level of the economy. While a-theoretic weights are often used to form such indexes, Anderson and Neary (2005) emphasize the practical importance of theoretically consistent weights. In this section, we briefly review the aggregation methods proposed by Agnosteva, Anderson and Yotov (2014). For expositional purposes, our focus will be aggregation across regions within the EU at a given point of time. However, similar principles apply for consistent aggregation over sectors.

The goal is to consistently aggregate bilateral trade costs $t_{i j}$ within the EU so as to preserve the aggregate export volume from $i$ to destinations $j$ in the subset of countries that belong to the EU, $j \in E U(i), j \neq i$. We follow Agnosteva, Anderson and Yotov (2014) and assume away the effect of changes in bilateral trade costs $t_{i j}, j \in E U(i)$ on the multilateral resistances $\Pi_{i}, P_{j}{ }^{27}$ Under this assumption, the volume equivalent uniform bilateral trade cost index $b_{E U(i)}$ is implicitly defined as:

$$
\sum_{j \in E U(i)} X_{i j}=\sum_{j \in E U(i)} \frac{Y_{i} E_{j}}{Y}\left(\frac{t_{i j}}{\Pi_{i} P_{j}}\right)^{1-\sigma}=\sum_{j \in E U(i)} \frac{Y_{i} E_{j}}{Y}\left(\frac{b_{E U(i)}}{\Pi_{i} P_{j}}\right)^{1-\sigma} .
$$

Focus on the middle and rightmost expressions. Divide each of them by $\left(Y_{i} / \Pi_{i}^{1-\sigma} Y\right) E_{E U(i)}$ and solve for $b_{E U(i)}$ :

$$
b_{E U(i)}=\left[\sum_{j \in E U(i)} \frac{E_{j} / P_{j}^{1-\sigma}}{\sum_{j \in E U(i)} E_{j} / P_{j}^{1-\sigma}} t_{i j}^{1-\sigma}\right]^{1 /(1-\sigma)}
$$

Equation (13) reveals that the EU regional trade cost aggregate is a weighted-average across the bilateral trade costs for the exporters in the EU region. The weights in Equation (13) can be interpreted in the spirit of the market access and market potential indexes from the economic geography literature, e.g. Redding and Venables (2004). From a practical perspective, the weights can be constructed directly from the importer fixed effects, $\chi_{j}$, in the estimating gravity equation (7), so that the aggregating equation becomes: ${ }^{28}$

$$
b_{E U(i)}=\left[\sum_{j \in E U(i)} \frac{\chi_{j}}{\sum_{j \in E U(i)} \chi_{j}} t_{i j}^{1-\sigma}\right]^{1 /(1-\sigma)}
$$

Expressing (14) in terms of importer fixed effects is important for two reasons. First, from a theoretical perspective, owing to the additive property of the PPML estimator, cf. Arvis and Shepherd (2013) and Fally (2015), the estimates of the gravity fixed effects correspond exactly to the structural gravity terms. Second, from a practical perspective, this implies that consistent aggregation of bilateral trade costs at any level can be obtained in three simple steps: (i) Estimate gravity with PPML; and (ii) construct bilateral trade costs for

\footnotetext{
${ }^{27}$ This assumption is particularly useful for practical purposes and it is justified for subsets with small trade volume shares. Alternatively, a more computationally intensive procedure should take into account the changes in the multilateral resistances that are driven by changes in bilateral trade costs.

${ }^{28}$ See Anderson, Larch and Yotov (2015) and Larch and Yotov (2016) for details.
} 
each pair; and (iii) aggregate bilateral trade costs at the desired level with the estimates of the importer fixed effects used as weights.

Applying the same principles and methods delivers a consistent aggregate of bilateral trade costs for the European Union on the demand side:

$$
b_{E U(j)}=\left[\sum_{i \in E U(j)} \frac{Y_{i} / \Pi_{i}^{1-\sigma}}{\sum_{i \in E U(j)} Y_{i} / \Pi_{i}^{1-\sigma}} t_{i j}^{1-\sigma}\right]^{1 /(1-\sigma)}=\left[\sum_{i \in E U(j)} \frac{\pi_{i}}{\sum_{i \in E U(j)} \pi_{i}} t_{i j}^{1-\sigma}\right]^{1 /(1-\sigma)},
$$

where, as can be seen from the rightmost expression, the aggregating weights are now the exporter fixed effects from the gravity regression. As a result, the first two steps of the practical aggregation procedure that we described above apply here directly. The only difference appears at step (iii), where instead of the importer fixed effects, the weights are the exporter fixed effects.

\section{Gravity Data: Sources and Limitations}

Gravity equations have been estimated using a variety of country-specific and bilateral variables as determinants of bilateral trade flows. The goal of this section is to review the main data sources and the data limitations that researchers have faced when using these sources. Following our recommendation that gravity should be estimated with exporter(-time) and importer(-time) fixed effects, and also for brevity purposes, we focus our discussion mainly on data for the dependent gravity variable, i.e. bilateral trade flows, and on data that can be used to construct proxies for bilateral trade distortions ${ }^{29}$ All web links for the data sources discussed in this section are provided as active links in Appendix B.

\subsection{Bilateral Trade Flows Data}

Traditionally, gravity estimations have mostly been performed with aggregate data. However, mainly due to availability of more and more reliable disaggregated data, we start to see more often sectoral and even product gravity analysis.

Aggregate Trade Flows Data. The primary source of information for aggregated (country-level) bilateral trade flows is the IMF'S Direction of Trade Statistics (DOTS). ${ }^{30}$ The database covers 184 countries. Annual data are available from 1947, while monthly and quarterly data start from 1960. Data are reported in US dollars. Relying on DOTS and other national sources of data, Barbieri and Keshk have created a database (Correlates of War Project) ${ }^{31}$ that tracks total national trade and bilateral trade flows (imports and exports) between states from 1870-2009 in current U.S. dollars.

\footnotetext{
${ }^{29}$ For country-specific data we refer the reader to IMF's International Financial Statistics (IFS), at http://data.imf.org/?sk=5DABAFF2-C5AD-4D27-A175-1253419C02D1, the World Bank's World Development Indicators (WDIs), at http://databank.worldbank.org/data/reports.aspx?source=world-developmentindicators the Penn World Tables (PWT), at http://www.rug.nl/research/ggdc/data/pwt. The last version of the Penn World Tables covers 182 countries for the period 1950-2014.

${ }^{30}$ http:/ / data.imf.org/?sk=9D6028D4-F14A-464C-A2F2-59B2CD424B85\&ss=13900303418545

${ }^{31}$ http://correlatesofwar.org/data-sets/bilateral-trade
} 
Merchandise Trade Flows Data. Availability of trade flows data at the disaggregated level depends on the sector in question. Data on merchandise trade flows are available at disaggregated level and for a long period of time for several data sources. The UN Commodity Trade Statistics Database (COMTRADE) ${ }^{32}$ is the most common source of data of disaggregated trade by commodity. It reports annual bilateral trade flow data expressed in gross value and volume from 1962 for more than 160 countries on average.33 Monthly data are also available since 2010. Trade values are in current US dollars converted from national currencies. Data are available online through the UN website or through the World Bank's World Integrated Trade Solution (WITS) portal [34 The data are accessible in different nomenclatures and in different levels of disaggregation. Trade data classified according to the Harmonised System (HS) are available up to the 6-digit level (that is, at a level of detail that distinguish about 5,000 separate goods items), which is the most disaggregated classification that is consistent across countries at the international level 35 Annual trade data are also classified using the Standard International Trade Classification (SITC). This classification focuses more on the economic functions of products at various stages of processing rather than the physical characteristics of a product. In its Rev. 4 version this classification reaches 5 digit (2,970 lines). Concordance tables exist to match data in HS and SITC classifications.

Measurement error is a standard problem with trade data. Import data have been traditionally more reliable because imports are monitored much more closely than exports by customs administrations, since the former are often subject to an import duty. Therefore, it is often advisable to use import data to construct the main dependent variable in gravity regressions and also to use "mirror data", that is to use imports data from destination countries as a measure of exports from origin countries. It should be noted, however, that mirroring may not be a good idea in cases when the importing country applies very high tariffs and has weak monitoring capability at customs. In these cases, the incentive to avoid tariffs and border controls may lead to largely underestimated import data. For this reason, it is not uncommon to have declared imports of country $j$ from exporter $i$ that are lower than the declared exports of $i$ to destination $j$, even though imports are reported at c.i.f prices. i.e. including cost, insurance and freight, and exports are reported at f.o.b prices, which stands for free on board, i.e. not inclusive of any costs associated with transportation.

In an attempt to reconcile declarations of importers and exporters in COMTRADE, CEPII has created the Base Analytique du Commerce International (BACI) ${ }^{36}$ In addition, the BACI data are also cleaned to exclude re-exports. The BACI database provides trade data at the 6-digit HS level for more than 200 countries from 1995. Because the construction and processing of the BACI data requires time and it is based on original data from other

\footnotetext{
${ }^{32} \mathrm{http}: / /$ comtrade.un.org

${ }^{33}$ Trade data can also be extracted from the ITC's Trade Map (http://www.trademap.org/Index.aspx). The GTIS' Global Trade Atlas (https://www.gtis.com/gta) also presents figures on merchandise trade, including bilateral trade, for over 65 countries from 1995 at the monthly, quarterly, biannual or annual frequency.

${ }^{34}$ http://wits.worldbank.org/Default.aspx?lang=en

${ }^{35}$ Some countries record data at more disaggregated HS levels, e.g. 8-digit or 10-digit. However, a consistent international data at these levels does not exist.

${ }^{36} \mathrm{http}: / /$ www.cepii.fr/cepii/en/bdd_modele/presentation.asp?id=1
} 
primary sources, e.g. COMTRADE, the BACI data are available to the public with a time lag of 1 or 2 years as compared to COMTRADE. Finally, to tackle the problem of measurement errors, the World Trade Flows (WTF) ${ }^{37}$ database developed by Feenstra and Romalis (2014) omits observation where the c.i.f/ f.o.b. ratio is either less than 0.1 or larger than 10 and where the c.i.f. value is smaller than 50,000 US dollars. This database contains bilateral trade data for 185 countries on average over the period 1984-2014.

Services Trade Flows Data. Bilateral trade flows data on services are still relatively limited. Nevertheless, there has been a significant effort and advances to offer such data. The OECD Trade in Services databas 38 offers data on bilateral services trade for 12 main services sectors and several sub-sectors according to Extended Balance of Payments (EBOPS) 2010 classification (146 categories in total). The OECD database covers 35 countries including 32 OECD member countries plus Russia, Colombia and Latvia from 1999 onwards. The UN Service Trade Database 39 covers 46 economies from 2000 onwards and follows EBOPS 2002 classification (114 categories: 86 standard items (11 main items), 24 memorandum items and 4 supplementary items). WTO, UNCTAD and ITC also jointly develop a database which contains bilateral annual service flows data for 36 countries at the same level of disaggregation as OECD data since 2005 according to EBOPS 2010. These bilateral data can be retrieved from the ITC TradeMap. An older version of this database, following the previous services classification (EBOPS 2002), covers the period 1980/2013. It presents data for 49 countries ${ }^{40}$ Finally, the Trade in Service database ${ }^{41}$ developed by Francois and Pindyuk includes bilateral service flows data for the period 1981-2010 and 248 countries on average. Data comes from OECD, Eurostat, UN and IMF. Adjustments have been made using mirroring, reconciliation of aggregated with underlying flows and consolidation (Francois and Pindyuk, 2013). Services are classified according to EBOPS2002 classification.

Agriculture and Resource Sectors Data. FAOSTAT collects information on annual basis in more than 100 countries. The Detailed Trade Matrix reports information on agricultural bilateral trade flows for over 600 food and commodities per year. It provides data for both quantities (in tons) and values (in thousands of US dollars) of agricultural import and exports. Data are available for the period 1986-2013 and are gathered from national sources.

Intra-national Trade Flows Data. As argued earlier in this paper, the use of intranational trade flows data is desirable and consistent with theory. However, such data are

\footnotetext{
${ }^{37} \mathrm{http}: / /$ www.robertfeenstra.info/data

${ }^{38}$ https://stats.oecd.org/Index.aspx?DataSetCode=TISP

${ }^{39}$ http://unstats.un.org/unsd/servicetrade/sysLogin.aspx

${ }^{40}$ OECD and WTO are currently working on building a global matrix of trade in services statistics. The dataset will include exports and imports of total services and of 11 main EBOPS2002 items, and will cover 191 reporters and partners for the period 1995-2012. Data are obtained from OECD, Eurostat, WTOUNCTAD-ITC and national sources. Missing observations are estimated using different techniques, such as backcasting, forecasting, interpolations, derivations, integration of EBOPS2010 data, as well as gravitymodel based estimates in order to obtain a complete, square matrix. An EBOPS2010 version of the dataset is also envisaged for the near future.

${ }^{41}$ https://ideas.repec.org/p/lnz/wpaper/20130101.html.
} 
not readily available and their use requires caution. Some countries, e.g. Canada ${ }_{42}^{42}$ have devoted significant resources and special attention to carefully constructing intra-national trade flows. However, constructing an international database of intra-national trade flows is challenging for at least two reasons. First, traditionally researchers have constructed intranational trade flows as apparent consumption, defined as the difference between production and total exports. However, aggregate production data are usually measured and reported as value added, e.g. GDP, while total exports are reported as gross value. This is why the production databases that we describe below are based on sectoral data, usually covering goods only, for which value added and gross values are available and reported. In addition, typically production data are classified using the Standard Industrial Classification (SIC). This nomenclature classifies products at the 4-digit level at the highest level of detail. Although concordance tables between various nomenclatures exist, matches are not perfect and one may need to move to higher levels of aggregation to guarantee a better match.

Despite these (and other) limitations, there have been efforts to merge bilateral trade and production data in order to construct consistent databases of international and intranational trade flows. Several examples for manufacturing production include: (i) the World Bank?s Trade, Production and Protection (TPP) database ${ }^{43}$ that covers approximately 100 countries, for the period 1976-2004 where information is available in Industrial Standard Industrial Classification (ISIC) Rev. 3 at the 3-digit level; (ii) The CEPII's Trade, Production and Bilateral Protection (TradeProd) ${ }^{44}$ that has figures for over 150 countries during the period 1980-2006 in ISIC Re. 2 at the 3-digits level; (iii) the UNIDO Industrial Statistics (INDSTAT), ${ }^{45}$ which reports data from 1962 onwards at the 2-digit level of ISIC Rev.3 (INDSTAT2) or from 1990 at the 4-digit level (INDSTAT4) onwards for 166 countries. Note that all these databases only cover goods sectors.46

\subsection{Bilateral Trade Costs Data}

As discussed earlier in this paper, one of the estimation challenges with gravity equations is to proxy for the unobservable bilateral trade costs $t_{i j, t}$ from the structural gravity model. Traditionally, the bilateral trade costs in a gravity equations are proxied by a series of observable variables that determine trade costs. Anderson and van Wincoop (2004) offer a thorough survey of trade costs. From a broad practical perspective, trade costs can be divided into

\footnotetext{
${ }^{42}$ Under the Project to Improve Provincial Economic Statistics (PIPES), Canada's government has created a database that includes consistent intra-national and international data for Canada's economy at the sectoral level for a total of 28 industries including agriculture, 17 manufacturing sectors, aggregate manufacturing, and 9 service categories for the period 1997-2007. See Genereux and Langen (2002) for further details.

${ }^{43}$ http://econ.worldbank.org/WBSITE/EXTERNAL/EXTDEC/EXTRESEARCH/0,,contentMDK:2108 5384 pagePK:64214825 ${ }^{\sim}$ piPK:64214943 ${ }^{\sim}$ theSitePK:469382,00.html. The database has been developed by Nicita and Olarreaga (2007).

${ }^{44}$ http://www.cepii.fr/CEPII/fr/bdd_modele/presentation.asp?id $=5$

${ }^{45}$ http://stat.unido.org

${ }^{46}$ The CEPII's CHELEM-International Trade database, https://chelem.bvdep.com/version-201634/cgi/ template.dll?product=111\&dummy_forcingloginisapi=1 contains data from 1967 and covers 94 countries. Sectoral data are classified according to the CHELEM nomenclature (71 sectors), GTAP (43 sectors) and ISIC classification (147 sectors). The CHELEM nomenclature has been built to allow a better correspondence between data on trade and production. However, unlike the first three databases, the CHELEM includes estimated observations, which means that it should not be used for gravity estimations.
} 
their time-varying and time-invariant components. Since, by nature, trade policy variables are time-varying, our focus in this section will be mainly on this component. However, we also note on the onset that most of the standard gravity variables that are routinely included in gravity estimations include time-invariant (or very slowly time varying) covariates such as physical distance, contiguous borders, common language, and common history and colonial ties. We refer the reader to the CEPII's GeoDist database ${ }^{47}$ which includes data on these variables for 225 countries, and to the accompanying paper by Mayer and Zignago (2011) for detailed information on these commonly used gravity covariates. In addition, we remind the reader that when panel data are available and the goal is identification of the effects of (time-varying) trade policies, our recommendation is to use pair fixed effects, which will absorb and control for the impact of all time-invariant determinants of trade flows.

For the rest of this section we focus on databases covering trade policy variables, which usually are divided in tariffs and non-tariff measures (NTMs). Data on various trade policies are available through three main portals: the World Bank's WITS; the WTO's Tariff and NTM portals; and the ITC's various web-based "Map" tools. Next, we offer details for data on specific trade policy measures.

\subsubsection{Tariff Data}

Tariffs can be classified into three groups: (i) MFN applied tariffs. MFN tariffs are imposed by a WTO member country on imports from other WTO members; (ii) MFN bound tariffs (the tariff ceiling above which countries have committed not to raise their applied tariff):48 and (iii) Preferential tariff rates (tariff countries have bilaterally negotiated under regional agreements). The WTO provides facilities to download tariff data for each of these three groups. Applied tariffs data notified to WTO can be found in the WTO's Integrated Data Base (IDB). The IDB contains data on MFN duties for applied and preferential duties for WTO member countries on an annual basis from 1996 onwards. Data are available at the tariff line level as reported by the country imposing these tariffs, i.e. more detailed than HS 6-digit level. The Consolidated Tariffs Schedules (CTS) database contains bound tariff, tariff quotas and export subsidies bound commitments at the tariff line level, as well as domestic support commitments. Access to the IDB and CTS databases is possible through WTO's Tariff Analysis Online (TAO) interface and for HS 6-digit pre-aggregated data through the Tariff Download Facility. The World Bank's WITS software 49 - developed in collaboration with UNCTAD, gathers together WTO's IDB and CTS database, UNCTAD's Trade Analysis

\footnotetext{
${ }^{47} \mathrm{http}: / /$ www.cepii.fr/cepii/en/bdd_modele/presentation.asp?id=6

${ }^{48}$ Bound rates are in general neglected in standard specifications of gravity models, as bound rates only reflect countries commitments but are not the tariffs that importers and exporters face when trading. Recent economic literature has, however, highlighted the importance that bound rates can have in determining a firm's decision to trade insofar as they affect the certainty of trading conditions. Exporters evaluate the risk associated with the possible increase in barriers to trade in the destination market when deciding whether to export, and delay exports to risky destinations. Trade policy uncertainty hinders trade and that advantages provided by lower applied tariffs can be limited in the presence of uncertainty Handley and Limao (2013), Handley (2014), and Osnago, Piermartini and Rocha (2015). A direct measure of trade policy uncertainty is the so-called "tariff water"-the gap between the bound and the applied tariff rate. Data on bound rates become recently relevant in this context.

${ }^{49} \mathrm{http}: / /$ wits.worldbank.org/
} 
Information System (TRAINS) data along with trade flows data from UN COMTRADE, data from Market Access Maps MacMar ${ }^{50}$ and OECD's Agriculture Market Access Database in a unique interface to facilitate data extraction.

Note that countries set tariffs at the tariff line level, which can be at the 6-, 8-, 9-, 10-, or 12-digit HS level depending on the country. To allow for cross country comparisons, to work with a dataset of a manageable size and/or to match the information with information available for other variable, such as bilateral trade flows, for example, researchers may need to aggregate tariffs. Two simple approaches include a simple average aggregation procedure and an import-weighted average methods. While simple and easy to implement, each of these procedures is subject to caveats. For example, when import-weighted averages are used to estimate the average degree of protection in a certain country, tariff lines with very high tariff will have a low weight, because imports subject to high protection rates are likely to be small. At the extreme, paradoxically, for a given level of total imports, the contribution to the import-weighted average tariff of goods subject to prohibitive tariffs is the same as the contribution of goods subject to zero tariffs. In fact, in both cases the product between the tariff and the level of import will be zero. Similarly, using the simple average method may also be misleading, because the tariff rate associated with a good that represents an important share of the total trade of a sector has the same impact on the calculated average tariff as that of a good that represents a minimal share of trade.

To tackle these aggregation problems, the ITC MAcMap database includes weighted tariffs at the HS 6 digit level that are calculated on the basis of a reference group weighting scheme. Five groups of reference countries have been identified according to the PPP GDP per capita and trade openness. Total imports by a given group are normalized to account for its size. Then, the measure obtained is used as weight to aggregate data across partners and products Bouet et al. (2005). MacMap includes tariff data (MFN and preferential) for the years 2005-20014 up to the national tariff line level for 190 countries.

\subsubsection{Data on Non-tariff Measures}

Non-tariff Measures have gained a more prominent role as trade and consumer protection tools in the current world economy. We start this section with a review of the main NTM databases. Then, we proceed with a discussion of specific NTM measures and databases that measure them. The five major NTM databases include:

- The UNCTAD's TRAINS database was the first comprehensive database on NTMs. The database covers import (technical and non-technical measures) and export measures as well as information on "procedural obstacles" 51 (i.e. administrative burdens, transparency issues or infrastructural challenges, etc.). Information in TRAINS is coded in a binary form at the tariff line level, which bears the limitation that the data does not allow to distinguish between mild and stiff non-tariff measures $5^{52}$

\footnotetext{
${ }^{50} \mathrm{http}$ ://www.cepii.fr/\%5C/anglaisgraph/bdd/macmap/form_macpmap/access.asp

${ }^{51}$ There are nine categories of procedural obstacles: (A) administrative burdens; (B) information/transparency: (C) inconsistent or discriminatory behavior of officials; (D) time constraint; (E) payment; (F) infrastructural challenges; $(\mathrm{G})$ security; $(\mathrm{H})$ legal constraints; (I) others (WTO, 2012)

${ }^{52}$ See WTO and UNCTAD (2012).
} 
- NTMs information can also be retrieved from the World Bank's TPP database. This database provides information on a set of "core non-tariff trade barriers (NTBs)" including price-control, finance control, and quantity control measures. Variables included in the database consist of frequency measures, coverage ratios, simple and importweighted ad-valorem equivalents of NTMs at the HS 3-digit level.53

- The CEPII's NTM-MAP database ${ }^{54}$ is also based on the UNCTAD's TRAINS data and it provides frequency measures, coverage ratios, and prevalence score ratios for technical barriers to trade (TBT), sanitary and phytosanitary (SPS) measures, pre-shipment inspections, contingent trade protective measures and non-automatic licensing, quotas, prohibitions, and quantity-control measures.

- The WTO Integrated Trade Intelligence Portal (I-TIP) $)^{55}$ includes information on antidumping, countervailing measures, quantitative restrictions, safeguard measures, tariff rate quotas, export subsidies, TBT and SPS measures. In addition, both TBTand SPS-IMS specific trade concerns (STCs) raised in their respective committees are shown. All information available through I-TIP refer to countries' notifications to WTO. Note that availability of information at the country level depends also on the country compliance to its notifications obligations. Since not all countries have the same propensity to notify their measures to the WTO, the picture of the NTMs in force in the notification database may then be biased.

- WTO's Trade Monitoring databas $\AA^{56}$ gathers information about trade-related measures (e.g. trade remedies, export duties, quantitative restrictions) implemented by WTO member countries after the 2008 global financial crisis.

- Finally, the Global Trade Alert databas ${ }^{57}$ reports policies that may affect trading partners' commercial interests, such as export incentives export taxes, import tariffs as well as NTMs.

Next, we discuss specific NTMs and the databases that have been constructed to measure them.

- Subsidies and government support measures. The OECD's Agricultural Policy database ${ }^{58}$ accounts for different measures of agricultural support, such as the total support estimate, producer support estimate; consumer support estimate and general services support estimate (GSSE) ${ }^{59}$ Data are available from 1986 onwards.

The WTO's Agriculture Information Management System 60 includes a series of measures notified by WTO member countries to the Agricultural Committee, including

\footnotetext{
${ }^{53}$ See Nicita and Olarreaga (2007) for further details on the TPP database.

${ }^{54}$ http://www.cepii.fr/CEPII/fr/publications/wp/abstract.asp?NoDoc $=7537$

${ }^{55}$ https://www.wto.org/english/res_e/statis_e/itip_e.htm.

${ }^{56} \mathrm{http}: / /$ tmdb.wto.org/searchmeasures.aspx?lang $=\overline{\mathrm{en}}-\mathrm{US}$

${ }^{57}$ www.globaltradealert.org/

${ }^{58}$ https://data.oecd.org/agrpolicy/agricultural-support.htm

${ }^{59}$ https://data.oecd.org/agrpolicy/agricultural-support.htm

${ }^{60}$ http://agims.wto.org/
} 
export subsides. These data are available over a twenty-year period (1995-2015). In addition, the WTO Consolidated Tariff Schedules (WTO-CTS) provides information about agricultural non-tariff commitments, which include tariff quotas and subsidies.

The International Energy Agency (IEA) website contains data about fossil fuel subsidies.61 The dataset covers oil, electricity, natural gas, coal and the total fossil fuels in billions of real US dollars over the period 2012-2014. The data also include estimates for the average subsidisation rate (per cent), subsidies per capita, and total subsidies as share of the GDP (per cent).

Finally, the World Bank presents data about aggregated subsidies and other transfers in current local currency unit (LCU) by country from 1981 to 2015.62 Subsidies, grants, and other social benefits reported include all unrequited, non-repayable transfers on current account to private and public enterprises; grants to foreign governments, international organizations, and other government units; and social security, social assistance benefits, and employer social benefits in cash and in kind 63

- Export restrictions. The OECD develops and maintains data on export restrictions for primary agricultural product: 64 as well as raw materials ${ }^{65}$ (minerals, metals, and wood). Data are aggregated at 6-digit level of HS2007. Various kinds of export restrictions are included, such as export duties, export prohibitions, and licensing requirements. Information on primary agriculture products covers the period 1996-2012, while data on raw materials restrictions are only available for the years 2009-2014.

- Safeguards and antidumping/countervailing measures. Chad Bown developed a series of useful databases hosted by the World Bank: the Global Anti-dumping (GAD) and the Global Countervailing Duties (GCVD) databases gather data for the period 1980s-2015, the China-Specific Safeguards (CSFG) includes information for the period 2002-2015, while the Global Safeguards (GSFG) and the WTO Dispute Settlement Understanding (WTO-DSU) Cases related to AD, SFG or CVD cover the period 19952015. The World Bank's Temporary Trade Barriers Database (TTBD) gathers all these databases together ${ }^{66}$

- Technical regulations and sanitary and phytosanitary measures. The WTO's TBT Information Management System (TBT-IMS) ${ }^{67}$ and the SPS Information Management System (SPS-IMS) ${ }^{68}$ also provide access to the TBT and SPS measures notified to the WTO as well as any documents submitted to and released in the respective committee. In addition, both TBT- and SPS-IMS report various specific trade concerns

\footnotetext{
${ }^{61}$ http://www.worldenergyoutlook.org/resources/energysubsidies/fossilfuelsubsidydatabase/.

${ }^{62}$ http://data.worldbank.org/indicator/GC.XPN.TRFT.CN

${ }^{63}$ See the World Bank's website for more details.

${ }^{64} \mathrm{http}: / /$ qdd.oecd.org/subject.aspx?Subject=ExportRestrictions_PrimaryAgriculture

${ }^{65} \mathrm{http}: / /$ qdd.oecd.org/subject.aspx?Subject=ExportRestrictions_IndustrialRawMaterials

${ }^{66}$ http://econ.worldbank.org/WBSITE/EXTERNAL/EXTDEC/EXTRESEARCH/EXTPROGRAMS/

EXTTRADERESEARCH/0,,contentMDK:22561572 〜 pagePK:64168182 piPK:64168060 theSitePK:544849,00.html

${ }^{67}$ http://tbtims.wto.org/

${ }^{68}$ http://spsims.wto.org/
} 
(STCs) raised in their respective committees ${ }^{69}$

- Services trade restrictiveness indices. The OECD Services Trade Restrictiveness Index (STRI) ${ }^{70}$ identifies policies restricting foreign entry and movement of people, and imposing barriers to competition and transparency as well as other measures. The index ranges from 0 (complete openness) to 1 (complete closeness). The World Bank's Service Trade Restriction Database 71 collects also information for different services trade policies in 103 countries and 5 main sectors (covering telecommunications, finance, transportation, retail, and professional services) and key modes of service supply for the period 2008-2010.72

WTO and the World Bank jointly develop the I-TIP Services database. ${ }^{73}$ This database provides information on members' commitments under the GATS, RTAs applied measures in services and service statistics. All modules permit searches by service sector. Sectors are classified according to the Services Sectoral Classification List, developed during the Uruguay Round. Sectors are divided in 12 groups and 160 sub-groups.

- Trade facilitation restrictions. Several databases are available for trade facilitation indicators. Information about trade costs arising from non-policy measures can be found in the World Bank's Doing Business (DB) database ${ }^{74}$ In particular, the DB "trading across borders" indicator includes data on time and costs for import and export, differentiating among documentary, border compliance, and domestic transport. This information is available for 189 countries for the period 2004 onward.

The OECD Trade Facilitation Indicators (TFIs) ${ }^{75}$ are strongly linked to the provisions of the WTO Trade Facilitation Agreement (TFA) provisions (WTO, 2015). The 16 indicators measure information availability, involvement of the trade community, advance ruling, appeal procedures, fees and charges, formalities (documents, automation, procedures), cooperation (internal and external) as well as consularization, governance and impartiality, transit (fees and charges, formalities, guarantees and agreements and cooperation). The database provides information on 152 countries in 2009 and 2015. TFIs range from 0 (worst performance) to 2 (best performance) ${ }^{76}$

The World Bank's Logistic Performance Index (LPI) ${ }^{77}$ focuses on the logistic friendliness of a country and ranks countries along six dimensions: customs; infrastructures; ease of arranging shipments; quality of logistics services; tracking and tracing; and

\footnotetext{
${ }^{69}$ Perinorm (http://www.perinorm.com/home/default.aspx?ReturnUrl=\%2fdefault.aspx) is a bibliographic database on national, European, and international standards in 23 countries. Perinorm is developed by the British Standards Institution, the Association Française de Normalisation, and the Deutsches Institut für Normung. Counts of bilateral shared standards are also available in this database.

${ }^{70}$ http://www.oecd.org/tad/services-trade/services-trade-restrictiveness-index.htm

${ }^{71}$ http://iresearch.worldbank.org/servicetrade/

${ }^{72}$ See Borchert, Gootiiz and Mattoo (2012) for further details on the World Bank's Service Trade Restriction Database.

${ }^{73}$ http://i-tip.wto.org/services/default.aspx

${ }^{74}$ http://databank.worldbank.org/data/reports.aspx?source=doing-business

${ }^{75}$ http://www.oecd.org/trade/facilitation/indicators.htm

${ }^{76}$ Detailed information on the database is available upon request from the developers.

${ }^{77}$ http://lpi.worldbank.org/
} 
timeliness (WTO, 2015). The database covers 160 countries in the years 2007, 2010, 2012 and 2014.

The WEF's Enabling Trade Index (ETI) ${ }^{78}$ assesses the extent to which economies have in place institutions, policies, infrastructure and services facilitating the flow of goods over borders and their destinations (WTO, 2015). It includes 79 indicators grouped into 4 areas: market access; border administration; infrastructure; and operating environment.

- Regional trade agreements. When countries form a regional trade agreement not only they apply lower tariffs, but they also cooperate on a number of other policy areas that reduce overall bilateral trade costs among member countries beyond the removal of explicit trade barriers. One way to take this into account is by including among the regressors in a gravity equation a dummy indicating whether or not there is a trade agreement in place between a specific dyad of countries. This is the approach that we will take in the applications section, where we will demonstrate that the effects of RTAs are still strong even after controlling for MFN tariffs.

Data on RTAs, including information about the agreement name, status, date of notification and of signature, signatories countries and link to the text of documents, may be retrieved from the WTO Regional Trade Agreements Information System (RTAIS) 79 WTO also provides information on unilateral regional trade agreements (that is trade agreements of non-reciprocal nature, such as the General System of Preferences (GSP) and sub-schemes for Least-Developed Countries (LDCs) through an online interface at http://ptadb.wto.org. Data on preference utilization rates are also available through the Tariff Analysis Online interface. The database covers all RTAs notified to WTO and in force. The RTA-IS database enables to search for RTAs by country and territory or criteria. RTAs are classified depending on whether they are related to goods, services or goods and services, as well as whether they are customs unions, free trade agreements, or partial scope agreements according to the definition of the WTO. On the basis of all RTAs notified to WTO from 1955 to 2015, Mario Larch developed and maintains a database on bilateral and multilateral regional trade agreements. 80 The database covers 468 agreements in total from 1950 onward and it is available in STATA format. Using the WTO RTA-IS as basis, Jeffrey Bergstrand also developed a database on Economic Integration Agreements (EIAs) ${ }^{81}$ Bergstrand's database categorizes bilateral EIA relationships during the period 1950-2005 for pairings of 195 countries using a multichotomous index, that distinguish among unilateral, bilateral agreements, FTA, customs unions and common markets.

While informative, the indicator variable treatment of RTAs cannot capture the fact that RTAs also differ in terms of what specific provisions they cover. In order to address this issue, indexes of the depth of RTAs can be built starting from basic information on the coverage of the agreements. In 2013, WTO has codified provisions

\footnotetext{
${ }^{78}$ https://knoema.com/atlas/sources/WEF?topic=Foreign-Trade

${ }^{79} \mathrm{http}: / /$ rtais.wto.org/UI/PublicMaintainRTAHome.aspx

${ }^{80}$ http://www.ewf.uni-bayreuth.de/en/research/RTA-data/index.html

${ }^{81}$ http://www3.nd.edu/ jbergstr/
} 
for a set 100 RTAs signed between 1958 and 2011. ${ }^{82}$ The dataset is an extension of the data of Horn, Mavroidis and Wijkström (2012). These authors identify 52 policy areas which they then classify into two groups. The first group of policy areas, called $\mathrm{WTO}+$ provisions, fall under the current mandate of the WTO, reconfirm existing commitments and provide for additional obligations. The second group of policy areas, which they denote as WTO-X provisions, refer to obligations that are outside the current mandate of the WTO. The codification also ascertains the legal enforceability of the PTA/RTA obligations. The idea is that the clearer, more specific and imperative the legal language used to express a commitment or undertaking, the more successfully it can be invoked by a complainant in a dispute settlement proceeding, and thus the greater likelihood of it being enforced ${ }^{83}$ Following this methodology, the World Bank's Global Preferential Trade Agreements (GPTA) ${ }^{84}$ extends the coverage of the RTAs to include 330 agreements. Data on RTAs depth of integration can also be retrieved from the DESTA database 85 This database, hosted by the World Trade Institute, has been developed by Elsig, Dür, Baccini and Milewicz. Up until now, the database covers 587 trade agreements during the period 1947-2010. Information recorded includes whether or not the agreements cover intellectual property rights, public procurement, standards, services, investments and competition. The database also provides an index to measure the depth of the agreement.

\section{Estimating the Effects of Trade Policy: Applications}

In this section, we follow the recommendations from Section 3 to obtain a series of gravity estimates including estimates of the effects of traditional gravity variables, e.g. distance, common language etc., estimates of the effects of globalization, estimates of the effects of RTAs, as a representative form of bilateral trade policy, and MFN tariffs, as a representative form of non-discriminatory trade protection policy, within the structural gravity model. ${ }^{86}$ The purpose of the applications presented here is primarily instructional, therefore we abstract from including comprehensive sets of trade policy variables but rather focus on the effects of specific covariates. In order to emphasize the importance of the various considerations that should be taken into account when estimating the effects of trade policy, we present each application as a sequence of estimating equations and corresponding results. Consistent with our recommendations from the previous section, all estimation results from the alternative gravity specifications presented here are obtained with panel data with intervals. In addition, we sequentially implement the rest of the best-practice recommendations (e.g. the PPML estimator, exporter-time fixed effects, importer-time fixed effects, etc.) and

\footnotetext{
${ }^{82}$ https://www.wto.org/english/res_e/publications_e/wtr11_dataset_e.htm

${ }^{83}$ For a detailed explanation of the methodology and limitations of the dataset, see Section D.2 of WTO (2011).

${ }^{84}$ http://wits.worldbank.org/gptad/database_landing.aspx

${ }^{85} \mathrm{http}: / /$ www.designoftradeagreements.org/www.designoftradeagreements.org/indexf908.html?page_id=884

${ }^{86}$ While gauging the effects of various forms of regional trade agreements and other bilateral trade policies is a popular topic and enjoys significant interest in the trade gravity literature, Heid, Larch and Yotov (2015) is the first known to us study that estimates the effects of non-discriminatory trade policy directly within the structural gravity model.
} 
we discuss their implications. Standard errors in all estimations are clustered by trading pair in order to account for any intracluster correlations at that level.

The sample that we employ in our experiments is a balanced panel that consists of 69 countries and covers aggregate manufacturing over the period 1986-2006. The sample combines data from several sources. Most importantly, it includes consistently constructed international and intra-national trade flows data, which was assembled and kindly provided to us by Thomas Zylkin. The original sources for the international trade data are the UN COMTRADE database and the CEPII TradeProd database. COMTRADE is the primary data source and TradeProd is used for instances when it includes positive flows for observations when no trade flows are reported in COMTRADE. Intra-national trade for each country is constructed as the difference between total manufacturing production and total manufacturing exports. Importantly, both of these variables are reported on a gross basis, which ensures consistency between intra-national and international trade. Three sources are used to construct the production data: the UN UNIDO INDSTAT database, the CEPII TradeProd database, and the World Bank's TPP database 88 Our data on regional trade agreements are constructed and provided by Mario Larch and is described in the Data section above. Finally, all standard gravity variables including distance, contiguous borders, common language, and colonial ties are from the CEPII Distances database. An important advantage of the CEPII database is that the weighted-average methods that are used to construct distance ensure consistency between the measures of intra-national and international distance. 89

\subsection{Traditional Gravity Estimates}

The first application that we consider demonstrates the importance of proper account for the multilateral resistances and it also compares estimation results from the OLS vs. PPML estimator. All estimates are obtained with data that cover international trade flows only, as is standard in the literature. We start our analysis with an empirical specification that includes the standard gravity variables and is estimated with the OLS estimator:

$$
\begin{aligned}
\ln X_{i j, t}= & \beta_{1} \ln D I S T_{i j}+\beta_{2} C N T G_{i j}+\beta_{3} L A N G_{i j}+\beta_{4} C L N Y_{i j}+ \\
& \beta_{5} \ln O U T P U T_{i, t}+\beta_{6} \ln E X P E N D_{j, t}+\epsilon_{i j, t} .
\end{aligned}
$$

\footnotetext{
${ }^{87}$ The dimensions of the data were predetermined by the availability of consistently constructed international and intra-national trade flows data. Our sample covers the following countries: Argentina, Australia, Austria, Belgium-Luxembourg, Bolivia, Brazil, Bulgaria, Cameroon, Canada, Chile, China, Colombia, Costa Rica, Cyprus, Denmark, Ecuador, Egypt, Finland, France, Germany, Greece, Hong Kong, Hungary, Iceland, India, Indonesia, Iran, Ireland, Israel, Italy, Japan, Jordan, Kenya, Kuwait, Macau, Malaysia, Malta, Mauritius, Malawi, Mexico, Morocco, Myanmar, Netherlands, Nepal, Niger, Nigeria, Norway, Panama, Philippines, Poland, Portugal, Qatar, Romania, Senegal, Singapore, South Africa, South Korea, Spain, Sri Lanka, Sweden, Switzerland, Tanzania, Thailand, Tobago, Trinidad, Tunisia, Turkey, Uruguay, United Kingdom, and the United States.

${ }^{88}$ For further details on the construction of the trade data we refer the reader to Baier, Yotov and Zylkin (2016).

${ }^{89}$ Consistency is ensured because each method uses population-weighted distances across the major economic centers within or across countries, respectively.
} 
Here: $\ln X_{i j, t}$ is the logarithm of nominal bilateral trade flows from exporter $i$ to importer $j$ at time $t$. As defined earlier, $\ln D I S T_{i j}$ is the logarithm of bilateral distance between trading partners $i$ and $j, C N T G_{i j}$ is an indicator variable that captures the presence of contiguous borders, $L A N G_{i j}$ is a dummy variable that takes a value of one if partners $i$ and $j$ share a common official language, and it is equal to zero otherwise, and $C L N Y_{i j}$ is an indicator for the presence of colonial ties. Finally, $\ln O U T P U T_{i, t}$ and $\ln E X P E N D_{j, t}$ are the logarithms of the values of exporter output and importer expenditure, respectively.

Estimation results from specification (16) are reported in column (1) of Table 1. Overall, the results are as expected. With an $R^{2}=0.76$, our econometric specification delivers the standard strong fit that we are used to see for empirical gravity models in the literature. The estimates on all covariates in equation specification (16) are statistically significant at any conventional level and have expected signs. Turning to specific estimates, we find that distance is a significant impediment to bilateral trade. The estimate of the effect of distance is statistically significant at any conventional level and virtually equal to the benchmark estimate of -1 as documented by Disdier and Head (2008) and Head and Mayer (2014). Sharing a common border, speaking the same official language, and sharing colonial ties all lead to higher international trade. These results are standard in the literature and are supported by the positive and significant estimates on CONTIG, LANG, and CLNY 90 Overall, the gravity estimates that we obtain are widely accepted in the literature and, therefore, establish the representativeness of our sample.

Turning to the estimates on the activity/size variables in specification (16), we see that the estimates on $\ln O U T P U T_{i, t}$ and $\ln E X P E N D_{j, t}$ are positive, as expected, and very precisely estimated. In terms of magnitude, the estimates on the size variables are very close to one, as predicted by the structural gravity model. However, we note that each of them is statistically different from one. A possible explanation for this result is that our output and expenditure covariates may account for dynamic forces in the panel specification, which, as demonstrated in Olivero and Yotov (2012) who model dynamics in the form of endogenous asset accumulation, lead to theoretical elasticities of trade flows with respect to these variables that are different from one. Finally, we note that, in terms of magnitude, each of the estimates from column (1) of Table 1 is readily comparable to the corresponding summary indexes from Head and Mayer (2014).

Our goal in the next specification is to account for the multilateral resistances. As discussed earlier, and as famously demonstrated by Anderson and van Wincoop (2003), failure to account for the MR terms may lead to severe biases in the estimates of the gravity variables. Our first attempt to control for the multilateral resistances is with the 'remoteness indexes' that we introduced and discussed in section 3.191

$$
\begin{aligned}
\ln X_{i j, t}= & \beta_{1} \ln D I S T_{i j}+\beta_{2} C N T G_{i j}+\beta_{3} L A N G_{i j}+\beta_{4} C L N Y_{i j}+\beta_{5} \ln O U T P U T_{i, t}+ \\
& \beta_{6} \ln E X P E N D_{j, t}+\beta_{7} R E M_{-} E X P_{i, t}+\beta_{8} R E M_{-} I M P_{j, t}+\epsilon_{i j, t} .
\end{aligned}
$$

Here, the new covariates on the exporter and on the importer side are constructed, respec-

\footnotetext{
${ }^{90}$ We refer the interested reader to Melitz (2008) and Melitz and Toubal (2014) for recent and more involved analysis of the effects of language on international trade.

${ }^{91}$ While we recognize that we should change the notation that we use for our coefficients and the error term when we move from specification (16) to specification (17), we chose not to do this for notational and expositional simplicity.
} 
tively, as the logarithms of output and expenditure-weighted averages of bilateral distance:

$$
R E M_{-} E X P_{i, t}=\ln \left(\sum_{j} D I S T_{i j} \times \frac{E_{j, t}}{Y_{t}}\right) \quad R E M_{-} I M P_{j, t}=\ln \left(\sum_{i} D I S T_{i j} \times \frac{Y_{i, t}}{Y_{t}}\right) .
$$

Estimates from specification (17) are reported in column (2) of Table 1. Three main findings stand out. First, we find that the estimates of the effects of the standard gravity variables and the activity covariates are qualitatively identical to those from column (1). The only notable difference is that the estimate on $C N T G$ is only marginally statistically significant in the new specification. Second, we note that there are significant quantitative differences between the estimates from columns (1) and (2). Specifically, we find that the estimates of the effects of distance are stronger in column (2), while the estimates of the effects of contiguity and common official language are smaller. These results suggest that the estimates from column (1), which did not account for the multilateral resistances were indeed biased as suggested by Anderson and van Wincoop (2003). Finally, we obtain large, positive and highly significant estimates of the remoteness indexes. This result is in accordance with our expectations and captures the intuitive relationship that, all else equal, regions that are more isolated/remote from the rest of the world would trade more with each other.

Next, we follow our best-practice recommendations and we take a more comprehensive approach to account for the multilateral resistances with an appropriate set of fixed effects:

$$
\ln X_{i j, t}=\beta_{1} \ln D I S T_{i j}+\beta_{2} C N T G_{i j}+\beta_{3} L A N G_{i j}+\beta_{4} C L N Y_{i j}+\pi_{i, t}+\chi_{j, t}+\epsilon_{i j, t},
$$

where $\pi_{i, t}$ denotes the vector of exporter-time fixed effects, which will account for the multilateral resistances. Note that the exporter-time fixed effects will also absorb the exporter value of output as well as all other observable and unobservable exporter-specific characteristics. Similarly, $\chi_{j, t}$ denotes the set of importer-time fixed effects, which will control for the inward multilateral resistances and will absorb importer expenditure as well as any other observable and unobservable importer-specific characteristics that may influence bilateral trade.

The estimates from specification (19) are reported in column (3) of Table 1, and they reinforce the message from the results in column (2), which only partially controlled for the multilateral resistances. The estimate of the negative impact of distance on trade flows from column (3) is larger than the corresponding numbers from columns (1) and (2), while the estimates of the effects of contiguous borders and common official language decrease further relative to the results from columns (1) and (2). In sum, based on the estimates from columns (1)-(3), we conclude that proper account for the multilateral resistances is indeed important for obtaining gravity estimates with our sample.

We finish with a specification that employs the full set of exporter-time and importer-time fixed effects, as in column (3), but uses the PPML estimator instead of OLS:

$$
X_{i j, t}=\exp \left[\beta_{1} \ln D I S T_{i j}+\beta_{2} C N T G_{i j}+\beta_{3} L A N G_{i j}+\beta_{4} C L N Y_{i j}+\pi_{i, t}+\chi_{j, t}\right]+\epsilon_{i j, t} .
$$

PPML estimates from specification (20) are reported in column (4) of Table 1 and point to two important findings. First, comparison between the OLS estimates in column (3) and 
the PPML estimates in column (4) reveals significant differences in terms of magnitudes, significance, and even signs. Overall, and despite the different samples used, our results are very similar to those from Table 5 of Santos Silva and Tenreyro (2006). Specifically, like them, we find that, as compared to the OLS numbers, the PPML estimate of the effect of distance is significantly smaller in absolute value, the estimate on $C N T G$ becomes statistically significant, and the estimate on $L A N G$ decreases in magnitude but remains significant ${ }^{92}$ The estimate of the effects of colony decrease in magnitude in both studies, however it becomes negative and marginally significant in our case. Second, and more important, the RESET p-values ${ }^{93}$ which we report in the bottom of Table 1 reveal that the PPML regression is the only one that passes the misspecification test. In sum, similar to Santos Silva and Tenreyro (2006), our estimates favor the PPML estimator over OLS.

\subsection{A Simple Solution to the 'Distance Puzzle' in Trade}

Despite its popularity and great predictive power, the gravity model has been subject to significant criticism on the basis that gravity estimates fail to capture the effects of globalization on international trade. Based on a meta-analysis of a rich data set of 1,467 distance estimates from gravity equations from 103 papers, Disdier and Head (2008) conclude that "the estimated negative impact of distance on trade rose around the middle of the century and has remained persistently high since then. This result holds even after controlling for many important differences in samples and methods" (p.37). The finding that the gravity estimates of the effects of distance on trade are stable (or even increasing) over time is known as the 'Distance Puzzle' in international trade. Coe et al. (2002) generalize this result to define the 'Missing Globalization Puzzle' as 'the failure of declining trade-related costs to be reflected in estimates of the standard gravity model of bilateral trade" (p.1). The same authors conclude that "globalization is everywhere but in estimated gravity models" (p.3). This application employs the methods from Yotov (2012) and reproduces some of the estimates from Borchert and Yotov (2016) in order to resolve the 'distance puzzle' of trade. ${ }^{94}$

Capitalizing on the properties of the structural gravity model, Yotov (2012) demonstrates that the distance puzzle is solved and that globalization is in fact present in gravity equations when the latter are estimated following the recommendations that we presented in Section 3.2. Yotov's idea is simple and intuitive. Specifically, he recognizes that since the gravity system can only ever identify relative trade costs, 95 all existing studies that try to resolve the distance puzzle suffer an important omission, namely, these studies estimate gravity based on samples that consist of international trade data only. Thus, by default, these studies cannot

\footnotetext{
${ }^{92}$ We remind the reader that the reported coefficients are not marginal effects for the dummy variables, neither for the PPML estimator nor for the semi-log OLS estimator. This potentially could also explain some of the differences between OLS and PPML.

${ }^{93}$ The Ramsey RESET test detects model specification errors, i.e. possible omitted variables. The null hypothesis (H0) states that the model does not suffer from misspecification errors. We can reject $\mathrm{H} 0$ when the p-value is smaller than the critical value and our model is not correctly specified. Conversely, we cannot reject the null hypothesis if the p-value is larger than the significance value.

${ }^{94}$ The distance puzzle has been of significant interest to the professions. See for example Buch, Kleinert and Toubal (2004), Carrère and Schiff (2005), Brun et al. (2005), Boulhol and de Serres (2010), Lin and Sim (2012), and Larch et al. (2016).

${ }^{95}$ The structural gravity system is homogeneous of degree zero.
} 
capture the declining effects of distance and the effects of globalization because these effects are measured relative to a baseline that also is subject to the same or similar globalization forces. Yotov (2012) argues that "the appropriate measure of globalization should be the increase in international economic integration relative to the integration of internal markets. Consequently, we need to evaluate the effects of bilateral distance and international trade costs relative to the effects of internal distance and internal trade costs in order to capture the effects of globalization" (p.2).

Yotov's idea is visualized in Figure 1, which depicts the evolution of domestic and international phone calls in Germany between 1956 and 1995. ${ }^{96}$ Assuming that communication costs and falling costs of connecting people have affected international phone calls in all countries similarly (uniformly), gravity estimations that use data on international flows only will not be able to capture theses effects, because the gravity estimates will be relative to a reference group that has been affected similarly (equally) by improved communications and technology. However, it is clear from the figure that the cost of international phone calls have fallen faster than the costs for domestic calls. Thus, an empirical model that allows for a decrease in international trade costs relative to internal trade costs is more likely to capture the effects of globalization, in the form of improved communication technologies. Mechanically, the simple adjustment proposed by Yotov (2012) that solves the distance puzzle is based on a stricter adherence to the structural gravity theory, which requires that internal trade and internal distance are accounted for in standard gravity estimations. Once this is done and the effects of international distance are measured relative to the effects of internal distance, the distance puzzle disappears. We demonstrate this with our sample next.

For expositional clarity and instructional purposes, we develop our analysis sequentially. We start with estimates that capture the distance puzzle as described in the literature. Then we move to specifications that follow Yotov (2012) and solve the puzzle. All estimation results related to this application are presented in Table 2 and some of them replicate the specifications from Table 1 in Borchert and Yotov (2016) but with data over 4-year intervals. ${ }^{97}$ The estimates in column (1) are obtained with the OLS estimator and use only international trade flows, i.e. for $i \neq j$, as is standard in the literature, and we allow for different effects of distance in each of the six years, $Y \in\{1986,1990,1994,1998,2002,2006\}$ in our sample:

$$
\ln X_{i j, t}=\sum_{Y=1986}^{2006} \beta_{Y} \ln D I S T_{-} Y_{i j}+\beta_{2} C N T G_{i j}+\beta_{3} L A N G_{i j}+\beta_{4} C L N Y_{i j}+\pi_{i, t}+\chi_{j, t}+\epsilon_{i j, t},
$$

The estimates in column (1) show that the negative impact of distance on bilateral trade actually increases a bit over time. This is captured by the percentage change in the distance estimates between 1986 and 2006, which we report in the bottom panel of Table 2 .

\footnotetext{
${ }^{96}$ This figure is borrowed from Borchert and Yotov (2016) who extract the picture from an extended figure that covers the years 1949-2005, which appears as Chart 11 at page 87 of the World Trade Report 2008.

${ }^{97}$ Borchert and Yotov (2016) expand on the methods from Yotov (2012) to offer a more robust approach to solving the distance puzzle. We apply their approach in our last specification below. In addition, the main focus of their analysis is to measure the effects of globalization on individual countries. Borchert and Yotov (2016) use panel data with 10-year intervals. Their findings suggest that globalization benefitted the more developed countries more, while some of the least developed countries actually suffered from the globalizing trends.
} 
$\% \Delta l n_{-} D I S T_{1986-2006}=7.950$ (std.err. 3.759) ${ }^{98}$ The results from column (1) are consistent with and confirm the presence of the 'distance puzzle' in our sample.

The estimates in column (2) are obtained with the same sample (international trade only) but this time with the PPML estimator.

$$
X_{i j, t}=\exp \left[\sum_{Y=1986}^{2006} \beta_{Y} \ln D I S T_{-} Y_{i j}+\beta_{2} C N T G_{i j}+\beta_{3} L A N G_{i j}+\beta_{4} C L N Y_{i j}+\pi_{i, t}+\chi_{j, t}\right]+\epsilon_{i j, t},
$$

The estimate of the effect of distance in 2006 is only marginally smaller in absolute value as compared to the corresponding index for 1986. However, as can be seen from the bottom panel of the table, the two distance estimates are not statistically different from each other, $\% \Delta l n_{-} D I S T_{1986-2006}=-2.750$ (std.err. 3.004). Thus, once again, we see evidence for the presence of the 'distance puzzle' in our data.

The estimates in column (3) of Table 2 follow the methods from Yotov (2012) and are obtained with international and intra-national trade data. In addition to resolving the distance puzzle, this simple adjustment to our sample will enable us to evaluate the impact of distance on internal trade and to compare these effects with the standard estimates of the effects of distance on international trade:

$$
\begin{array}{r}
X_{i j, t}=\exp \left[\sum_{Y=1986}^{2006} \beta_{Y} \ln D I S T_{-} Y_{i j}+\beta_{2} C N T G_{i j}+\beta_{3} L A N G_{i j}+\beta_{4} C L N Y_{i j}\right] \times \\
\exp \left[\beta_{5} \ln \_D I S T_{-} I N T R A+\pi_{i, t}+\chi_{j, t}\right]+\epsilon_{i j, t} .
\end{array}
$$

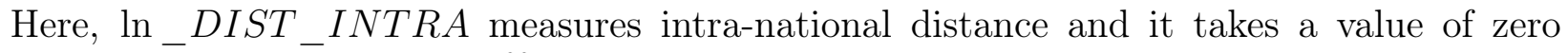
for international trade flows 99 Two main results stand out from the estimates in column (3). First, we find that the impact of internal distance on domestic sales is much smaller as compared to the distance effects on international trade. This is consistent with the estimates from Anderson, Vesselovsky and Yotov (2016) for the effects of intra-provincial vs. international distance in the case of Canada, and with the argument from Head and Mayer (2013) that international distance accounts for a host of obstacles to trade. Second, and more important for the current purposes, we obtain a significant decrease, in absolute value, of the effects of distance on trade between 1986 and 2006. Specifically, our estimates suggest that the effect of distance as an impediment to trade has fallen significantly by $\% \Delta l n_{-} D I S T_{1986-2006}=-10.965$ (std.err. 1.058) over the period 1986-2006.

Next, we improve on the specification from Yotov $(2012)$ by better accounting for potential forces that affect international relative to internal trade in addition to distance.100 Specifically, we add more border controls in the last two columns of Table 2. First, in column (4) we introduce the dummy variable $S M C T R Y$, which takes a value of one for intra-national trade, and it is equal to zero for international trade. The addition of this covariate is motivated by three reasons: (i) By adding it we allow for home bias effects. (ii)

\footnotetext{
${ }^{98}$ Standard errors for the percentage changes are obtained with the Delta method.

${ }^{99} \mathrm{We}$ remind the reader that internal and international distances are constructed consistently using the same population-weighted measures as discussed in the description of our data.

${ }^{100}$ Borchert and Yotov (2016) capitalize on and expands the methods from Yotov (2012) to study the uneven effects of globalization on trade by obtaining country-specific globalization effects.
} 
In addition, we try to capture any other effects that affect international trade differentially, which have not been covered by the other covariates in our model. (iii) Finally, as noted by Anderson and Yotov (2010), using the intra-national trade dummy has the advantage of being exogenous variables that picks up all the relevant forces that discriminate between intra-national and international trade. Consistent with the standard treatment of internal trade costs in the trade literature, we impose a common coefficient on $S M C T R Y$. This, in effect, can be interpreted as setting intra-national trade costs to be equal (and equal to zero) across the countries in our sample.

$$
\begin{array}{r}
X_{i j, t}=\exp \left[\sum_{Y=1986}^{2006} \beta_{Y} \ln D I S T_{-} Y_{i j}+\beta_{2} C N T G_{i j}+\beta_{3} L A N G_{i j}+\beta_{4} C L N Y_{i j}\right] \times \\
\quad \exp \left[\beta_{5} \ln \_D I S T_{-} I N T R A+\beta_{6} S M C T R Y+\pi_{i, t}+\chi_{j, t}\right]+\epsilon_{i j, t} .
\end{array}
$$

Three findings stand out from the estimates in column (4). First, as expected, we obtain a large, positive, and significant estimate on $S M C T R Y$, suggesting a significant 'home bias' in trade. Our estimate suggests that, on average across countries, intra-national trade is about 5.5 times $\left(e^{1.689}\right)$ larger as compared to international trade. This estimate is significantly smaller as compared to the famous border estimate of 22 for inter-provincial trade within Canada relative to international trade between Canadian provinces and US states from McCallum (1995). The proper econometric specification of the structural gravity model, e.g. controlling for the MR terms as suggested by Anderson and van Wincoop (2003) employed in this application is a natural candidate to explain our result. Second, we see that the estimates on international distance fall in absolute magnitude, while the impact of internal distance increases in absolute magnitude, and they converge toward each other in terms of magnitude. The intuition for this result is that (i) international distance has indeed been capturing more than just the effects of transportation costs, and (ii) the estimate on internal distance from the previous column has also been capturing 'home bias'. Finally, and most important, we find that the effects of distance have, once again, fallen significantly over time, $\% \Delta l n \_D I S T_{1986-2006}=-11.969$ (std.err. 1.173), i.e. the 'distance puzzle' has disappeared.

The last specification in Table 2 follows Borchert and Yotov (2016) and adds countryspecific fixed effects for intra-national trade, $\mu_{i i}$, i.e. for each country in our sample we add a dummy variable that takes a value of one for intra-national trade, and it is equal to zero otherwise 101 These fixed effects will absorb internal distance as well as the SMCTRY variable due to perfect collinearity. Thus, this specification allows for country-specific intranational trade costs and 'home-bias' effects. In addition, the country-specific dummies will control for any other country-specific time-invariant characteristics that may drive a wedge between internal and international trade. We view the following as our most comprehensive

\footnotetext{
${ }^{101}$ Some recent studies, e.g. Anderson et al. (2014) and Agnosteva, Anderson and Yotov (2014), obtain region-specific estimates of $S M C T R Y$ and document wide variation of those estimates across countries (Anderson et al. 2014) and even across provinces within Canada (Agnosteva, Anderson and Yotov, 2014). Related studies, e.g. Ramondo, Rodríguez-Clare and Saborío-Rodríguez (2014), investigate the implications of intra-national trade costs for international trade and welfare.
} 
specification 102

$$
\begin{gathered}
X_{i j, t}=\exp \left[\sum_{Y=1986}^{2006} \beta_{Y} \ln D I S T_{-} Y_{i j}+\beta_{2} C N T G_{i j}+\beta_{3} L A N G_{i j}+\beta_{4} C L N Y_{i j}\right] \times \\
\exp \left[+\mu_{i i}+\pi_{i, t}+\chi_{j, t}\right]+\epsilon_{i j, t} .
\end{gathered}
$$

Estimation results from specification (25) are reported in column (5) of Table 2. Our results reveal that the effects of distance are smaller as compared to the estimates from previous columns. This, once again, offers evidence that the estimates of the effects of distance in standard gravity regressions reflect more than just the effects of transportation costs. In addition, and also as before, we find that the effects of distance decrease significantly between 1986 and 2006, \% $\Delta l n \_D I S T_{1986-2006}=-10.931$ (std.err. 0.769). In sum, the estimates from Table 2 support the main argument from Yotov (2012) that once the effects of distance on international trade are measured properly, i.e. relative to intra-national trade, the distance puzzle is resolved and it disappears.

\subsection{Estimating the Effects of Regional Trade Agreements}

The goal of our third application is to obtain estimates of the effects of regional trade agreements. Once again, we proceed in steps. We start with a basic OLS specification. Then, capitalizing on various contributions from the literature, each additional step introduces a new feature to our specification. Our initial estimating equation includes all standard gravity variables that we introduced before, including the logarithm of bilateral distance $\left(\ln D I S T_{i j}\right)$, and the indicator variables for contiguous borders $\left(C N T G_{i j}\right)$, common official language $\left(L A N G_{i j}\right)$, and colonial ties $\left(C L N Y_{i j}\right)$. In addition, we also introduce a dummy variable that accounts for the presence of regional trade agreements between the countries in our sample and can be viewed as a representative bilateral trade policy. ${ }^{103} R T A_{i j, t}$ takes a value of one if countries $i$ and $j$ are partners in an RTA at time $t$, and it is equal to zero otherwise. We start with a traditional OLS specification:

$\ln X_{i j, t}=\beta_{1} \ln D I S T_{i j}+\beta_{2} C N T G_{i j}+\beta_{3} L A N G_{i j}+\beta_{4} C L N Y_{i j}+\beta_{5} R T A_{i j, t}+\pi_{i, t}+\chi_{j, t}+\epsilon_{i j, t}$.

We estimate equation (26) with data on international trade flows only. Furthermore, we use exporter-time and importer-time fixed effects in order to control for the multilateral resistances. Estimation results from Equation (26) are reported in column (1) of Table 3. Two main findings stand out. First, we note that the estimates of the effects of the standard gravity variables are in accordance with our expectations and also consistent with our findings from the previous applications. Second, interestingly, the estimates from column (1) of Table 3 suggest that regional trade agreements play no role in promoting international trade. The estimate on $R T A\left(\hat{\beta}_{5}=-0.004\right.$, std.err. 0.054) is small in magnitude (in fact negative) and not statistically significant. One possible explanation for this result is that specification (26)

\footnotetext{
${ }^{102}$ In principle, one may allow for time-varying SMCTRY effects. See Anderson et al. (2015) for example. This is beyond the scope of this application where, consistent with the motivation provided in Figure 1 . we prefer to keep the effects of intra-national trade costs constant over time.

${ }^{103}$ As discussed earlier, in the data section, our RTA variable is constructed by Larch and it covers all forms of trade agreements including free trade agreements, customs unions, etc.
} 
does not account properly for the potential endogeneity of RTAs. We address this issue later. Before that, we use the same sample to obtain RTA estimates with the PPML estimator:

$\ln X_{i j, t}=\exp \left[\beta_{1} \ln D I S T_{i j}+\beta_{2} C N T G_{i j}+\beta_{3} L A N G_{i j}+\beta_{4} C L N Y_{i j}+\beta_{5} R T A_{i j, t}+\pi_{i, t}+\chi_{j, t}\right]+\epsilon_{i j, t}$,

The PPML results are reported in column (2) of Table 3 . The estimates of the standard gravity variables are virtually identical to the corresponding numbers from column (4) of Table 1, which did not include the RTA covariate. This suggests that the omission of the RTA covariate has not biased the estimates from our first application. In addition, we obtain a positive and significant estimate of the effects of regional trade agreements $\left(\hat{\beta}_{5}=0.191\right.$, std.err. 0.066), suggesting that, all else equal, RTAs increase trade between member countries by about $21 \%,\left[e^{\hat{\beta}_{5}}-1\right] \times 100$. While positive and statistically significant, the estimate of the effect of RTÁs that we obtain is smaller than expected, based on corresponding numbers from the literature. 104

In our next experiment we follow Dai, Yotov and Zylkin (2014) and Anderson and Yotov (2016) and we expand the sample from the previous specification to include intra-national trade flows data in addition to international trade flows. The idea is that RTAs may be diverting trade from domestic to international sales and, therefore, the RTA estimates that are based on international trade only may be biased downward. Estimates from this experiment are reported in column (3) of Table 3. The estimates on the standard gravity variables in column (3) are not statistically different from the corresponding numbers in column (2). However, importantly, we note that the estimate of the effect of RTAs has more than doubled in magnitude, $\left(\hat{\beta}_{5}=0.409\right.$, std.err. 0.069). This result supports our hypothesis that regional trade agreements do indeed create trade between members at the expense of domestic sales. For further analysis of the effects of RTAs on trade creation and trade diversion we refer the reader to Dai, Yotov and Zylkin (2014).

Next, we apply the methods of Baier and Bergstrand (2007) in order to address the issue of RTA endogeneity, which, as discussed earlier in Section 3.1, may plague RTA gravity estimates. To do this, we follow our best practice recommendations and we add pair fixed effects on top of the theoretically-motivated importer-time and exporter-time fixed effects in the following estimating gravity equation:

$$
X_{i j, t}=\exp \left[\beta_{5} R T A_{i j, t}+\pi_{i, t}+\chi_{j, t}+\mu_{i j}\right]+\epsilon_{i j, t} .
$$

Estimation results are reported in column (4) of Table 3. As noted earlier, the use of pair fixed effects does not allow the inclusion of any of the standard gravity variables and, therefore, we cannot obtain estimates of their effects. In addition, due to perfect collinearity, one of the bilateral fixed effects need to be dropped. We choose to drop the fixed effect for internal trade $\mu_{i i}$, which corresponds to the SMCTRY indicator from specification (24). ${ }^{105}$

\footnotetext{
${ }^{104}$ See Baier and Bergstrand (2007) for estimates with aggregate data and Anderson and Yotov (2016) for sectoral manufacturing estimates.

${ }^{105}$ When individual, country-specific fixed effects are used instead of a single SMCTRY variable, one needs to drop all country-specific dummies for intra-national trade. This will have no effect on the estimates from column (4) of Table 3 .
} 
In effect, this implies that all internal trade costs are set to one and all international fixed effects $\mu_{i j}, j \neq i$, are estimated relative to $\mu_{i i}$.

Without going into details, we note that the estimates of all pair fixed effects (which we do not report for brevity) are negative and smaller and -1 . These results reflect the fact that the pair fixed effects absorb all trade costs and that international trade costs are larger as compared to intra-national trade costs. ${ }^{106}$ More important for our purposes and from a trade policy perspective, specification (28) delivers a positive and highly significant estimate of the effects of RTAs, $\left(\hat{\eta}_{1}=0.557\right.$, std.err. 0.102), which is larger than the RTA estimates from previous columns. This result is in accordance with the predictions from Baier and Bergstrand (2007) that RTA estimates that are obtained without proper account for endogeneity are biased downward. The RTA estimate from column (4) suggests that, all else equal, the formation of regional trade agreements leads to an average increase of about $75 \%,\left(e^{0.557}-1\right) \times 100$, in international trade between members, which is much closer to existing estimates from the literature.

In order to test whether the specification with pair fixed effects has accounted properly for possible 'reverse causality' between trade and RTAs, we follow Wooldridge (2010) and Baier and Bergstrand (2007) to implement an easy test for the "strict exogeneity" of RTAs. Specifically, we add a 'future lead' of RTAs, $R T A_{i j, t+4}$, to specification (28) and estimate:

$$
X_{i j, t}=\exp \left[\beta_{5} R T A_{i j, t}+\beta_{6} R T A_{i j, t+4}+\pi_{i, t}+\chi_{j, t}+\mu_{i j}\right]+\epsilon_{i j, t} .
$$

If RTAs are exogenous to trade flows, $R T A_{i j, t+4}$ should be uncorrelated with the current trade flow. Column (5) of Table 3 reports our findings, which reveal that the estimate of the future level of RTA is neither economically nor statistically different from zero. Similar to Baier and Bergstrand (2007), we interpret this as evidence that reverse causality is not present in our specification.

Our next specification introduces the lags of the RTA variable. The idea is to allow for non-linear RTA effects and/or to capture the phasing-in process, i.e. the possibility that the effects of RTAs decrease over time.

$$
X_{i j, t}=\exp \left[\beta_{5} R T A_{i j, t}+\beta_{6} R T A_{i j, t-4}+\beta_{7} R T A_{i j, t-8}+\beta_{8} R T A_{i j, t-12}+\pi_{i, t}+\chi_{j, t}+\mu_{i j}\right]+\epsilon_{i j, t} .
$$

In accordance with findings from existing related studies, ${ }^{107}$ our estimates offer evidence of strong phasing-in effects of RTAs. Specifically, we find a non-monotonic relationship, where the relatively small average effects of RTAs over the first years after the RTAs have come into force more than double in the second four-year period, and decrease almost three times as compared to their pick after twelve years. In sum, our estimates demonstrate that the effects of RTAs are non-monotonic and also capture phasing-in. The overall RTA effect, reported in the bottom panel of Table 3 is strong and our estimates suggest that the effects of RTAs remain significant twelve years after their implementation. We refer the reader to Baier and Bergstrand (2007) for further discussion of the phasing-in effects of RTAs.

\footnotetext{
${ }^{106}$ We refer the reader to Larch and Yotov (2016) for a discussion and demonstration of how the estimates of the pair fixed effects can be used to recover the full matrix of bilateral trade costs.

${ }^{107}$ See for example Baier and Bergstrand (2007) and Anderson and Yotov (2011).
} 
In our final experiment, we apply the methods of Bergstrand, Larch and Yotov (2015), who demonstrate that the effects of RTAs from specification (30) may be biased upward because they may be capturing the effects of globalization. Bergstrand, Larch and Yotov (2015) propose a simple adjustment to specification (30) in order to account for the effects of globalization:

$$
\begin{aligned}
X_{i j, t}= & \exp \left[\beta_{5} R T A_{i j, t}+\beta_{6} R T A_{i j, t-4}+\beta_{7} R T A_{i j, t-8}+\beta_{8} R T A_{i j, t-12}+\sum_{Y=1986}^{2002} \beta_{Y} I N T L_{-} B R D R \_Y_{i j}\right] \times \\
& \exp \left[\pi_{i, t}+\chi_{j, t}+\mu_{i j}\right]+\epsilon_{i j, t} .
\end{aligned}
$$

Here, the new covariate, $I N T L_{-} B R D R_{-} Y_{i j}$, is an indicator variable that takes a value of one for international trade, and it is equal to zero otherwise, for each year $Y$ in our sample. We remind the reader that, in order to allow for adjustment in trade flows, we use four year intervals, so in our sample $Y \in\{1986,1990,1994,1998,2000,2002,2006\}$. We also note that due to perfect collinearity with the rest of the fixed effects from specification (32), we are not able to obtain estimates of all border dummies, and we need to drop one of them. We choose to drop the international border dummy for 2006. Thus, the estimates of the other border variables should be interpreted relative to the corresponding estimate for 2006 .

Our findings are reported in Column (6) of Table 3. We focus on the two main results. First, we note that while the RTA estimates remain positive, they all decrease in magnitude. Furthermore, only the estimate of the first lag $\left(R T A_{i j, t-4}\right)$ remains statistically significant. The economic interpretation is that, once globalization forces are accounted for, the effect of RTAs take time to show in the data and also that they phase-in faster. Comparison between the total RTA effects with and without account for the globalization forces, i.e. comparison between the estimates from columns (5) and (6) in the bottom panel of Table 3, reveals that the total RTA effects are slashed in half once globalization forces are accounted for. This result suggests that the estimates of RTAs in our previous specifications may have indeed captured the effects of globalization, and it is consistent with the estimates from Bergstrand, Larch and Yotov (2015), which are obtained with a different sample.

Second, the estimates of the international border variables reveal that borders have fallen significantly over time. To see this, we remind the reader that these estimates should be interpreted as deviations from the border effect in 2006, which is our reference group. Thus, for example, the estimate on $I N T L_{-} B R D R \_1986$, suggests that the effects of borders on trade in 1986 were twice larger $(\exp (0.706)=2.026)$ as compared to the corresponding effects in 2006. Our estimates of the trend in the border are similar to those from Bergstrand, Larch and Yotov (2015) and suggest a steady and strong effect of globalization on trade over time. In sum, the estimates on the border variables in Column (7) of Table 3 offer a convincing counter-argument in response to the claim from Coe et al. (2002) that "globalization is everywhere but in estimated gravity models".

\subsection{Estimating the Effects of Unilateral Trade Policy}

We finish with an application that follows Heid, Larch and Yotov (2015) who demonstrate that the gravity model can be used to estimate the effects of non-discriminatory trade policies. To develop our analysis we focus on MFN tariffs, however the same methods can be used to 
study the impact of any non-discriminatory (across trading partners) trade policy either on the exporter or on the importer side, e.g. export subsidies vs. MFN tariffs. We focus on MFN tariffs for the following reasons. First, MFN tariffs fit the definition of non-discriminatory trade policy. Second, MFN tariffs are one key trade policy measure under negotiations at WTO. Third, MFN tariffs act as direct price shifters, which will enable us to recover an estimate of the trade elasticity of substitution from the estimate on MFN tariffs within the structural gravity model. Our data on MFN tariffs cover 52 of the 69 countries in the original sample and are available for the years 1988-2006.108 In order to take better advantage of the data, in this application we employ 3-year intervals covering the years 1988, 1991, 1994, 1997, 2000, 2003, and 2006.

Estimates from three specifications related to this application are reported in Table (4). The first column of the table uses the new sample to reproduce the estimates from column (6) of Table 3. Despite the differences in the country and time coverage, the two sets of estimates are very similar to each other. In particular, we obtain positive and significant estimates of the effects of all RTA variables. In addition, we see that the new results capture the phasing-in of RTAs, as suggested by the falling RTA estimates. Finally, we find that the total RTA effect from column (1) of Table (4), (0.955, std.err. 0.094), is almost identical to the corresponding index from Table (3), (0.992, std.err. 0.094). The only notable difference between the RTA estimates from the two tables is that the estimate of the current RTA effects with the new, smaller sample is larger while the estimate of the first RTA lag is smaller in column (1) of Table 4.

Next, in column (2) of Table 4, we introduce MFN tariffs, as a representative nondiscriminatory trade protection policy, in addition to the RTAs variables and their lags:

$$
\begin{aligned}
X_{i j, t}= & \exp \left[\eta_{1} R T A_{i j, t}+\eta_{2} R T A_{i j, t-3}+\eta_{3} R T A_{i j, t-6}+\eta_{4} R T A_{i j, t-9}+\eta_{5} \ln { }_{-} M F N_{j, t} \times I N T L_{i j}\right] \times \\
& \exp \left[+\pi_{i, t}+\chi_{j, t}+\mu_{i j}\right]+\epsilon_{i j, t} .
\end{aligned}
$$

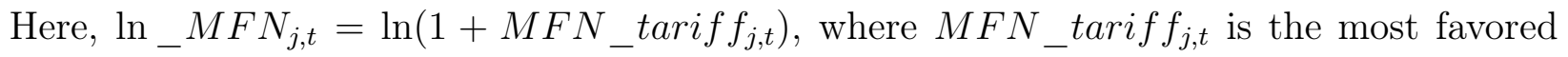
nation tariff imposed by importer $j$ at time $t$, and $I N T L_{i j}$ is a dummy variable that takes a value of one for international trade flows, and it is equal to zero otherwise. Estimation results from specification (32) are presented in column (2) of Table 4. Two main findings stand out. First, we note that the estimates of the RTA effects are still mostly positive and statistically significant. However, there is one important difference. Specifically, we note that the estimate of the current RTA dummy decreases in magnitude. In fact, it becomes negative and marginally significant. The rest of the RTA estimates are not statistically different from the corresponding indexes from column (1), which are obtained from a specification that does not control for MFN tariffs. Our estimates suggest that the contemporaneous RTA effects have been driven by the removal of MFN tariffs while the phasing-in effects are independent of the initial MFN tariff levels. Investment and deepening trade partnerships in response the the formation of RTAs are possible candidates to explain this interesting result, which is in support of the common belief that RTAs promote bilateral trade beyond the elimination of tariffs.

Second, and more important for our purposes, we obtain a negative and statistically significant estimate on $\ln \_M F N_{j, t},\left(\hat{\eta}_{4}=-6.673\right.$, std.err. 0.669), which (i) suggests that

\footnotetext{
${ }^{108}$ The data on MFN tariffs were constructed and kindly provided to us by Thomas Zylkin.
} 
MFN tariffs are an important impediment to international trade, and (ii) enables us to recover an estimate of the trade elasticity of substitution $\hat{\sigma}=6.7$, which fits comfortably within the distribution of corresponding estimates from the literature. 109 The fact that we are able to obtain an estimate of the elasticity of substitution, which, as discussed earlier, has gained popularity as the single most important trade parameter Arkolakis, Costinot and Rodríguez-Clare, 2012), directly from the structural gravity model is a very nice feature of our empirical specification. In addition, this is also a very important link that will ensure consistency between the partial equilibrium estimations and general equilibrium analysis that can be performed with the structural gravity model.

\section{Conclusion}

Proper measurement of trade costs and estimation of the partial equilibrium effects of trade policies are crucial components of a competent policy analysis. However, despite the continued interest in the gravity model of international trade and the advancement of empirical gravity literature, many estimations of the gravity model found in the literature remain biased and even inconsistent. The primary objective of this manuscript was to serve as a practical guide for estimations with the structural gravity model. We attempted to achieve this goal by reviewing the challenges with gravity estimations, by discussing leading databases for trade policy analysis with gravity models, by offering a list of best practice recommendations and a comprehensive and theoretically-consistent estimating gravity equation, and by demonstrating the usefulness of the methods that we describe here with a series of applications.

We believe that our analysis reflects the significant progress that has already been made in the area of measuring trade costs. At the same time, we see at least two opportunities for further improvements. One such area is the assessment of intra-national trade costs. Most of the current literature treats countries as point masses. Some recent efforts to tackle this unsatisfactory assumption include Donaldson (2016), Agnosteva, Anderson and Yotov (2014), and Ramondo, Rodríguez-Clare and Saborío-Rodríguez (2014). However, our understanding of intra-national trade costs and their impact on trade and welfare is still limited. Reconciling the estimates of trade costs that we obtained here with the calibrated ratio measures of trade costs is another under-explored area that has significant potential for important impact in trade policy analysis. Methods that successfully integrate the two approaches (estimation vs. calibration) to measuring trade costs will enable policy makers to obtain own estimates of the partial effects of specific trade policies of interest while matching the actual trade data at the same time. At the least, such methods will reveal our limitations in measuring trade costs and point to directions for improvement in research and policy action.

\footnotetext{
${ }^{109}$ The elasticity estimates from the related trade literature usually vary between 2 and 12 . See Eaton and Kortum (2002), Anderson and van Wincoop (2003), Broda, Greenfield and Weinstein (2006). Costinot and Rodríguez-Clare (2014), and Head and Mayer (2014) summarize the estimates of $\sigma$ and offer insightful discussions. The estimate of the elasticity of substitution under the assumption that tariffs are resource consuming, i.e. when tariffs are treated as iceberg trade costs, would be $\hat{\sigma}=7.7$.
} 


\section{References}

Agnosteva, Delina E., James E. Anderson, and Yoto V. Yotov. 2014. "Intra-national Trade Costs: Measurement and Aggregation." NBER Working Paper No. 19872.

Aichele, Rahel, Gabriel J. Felbermayr, and Inga Heiland. 2014. "Going Deep: The Trade and Welfare Effects of TTIP."

Anderson, James E. 1979. "A Theoretical Foundation for the Gravity Equation." American Economic Review, 69(1): 106-116.

Anderson, James E., and Eric van Wincoop. 2001. "Borders, Trade, and Welfare." Brookings Trade Forum, 207-230.

Anderson, James E., and Eric van Wincoop. 2003. "Gravity with Gravitas: A Solution to the Border Puzzle." American Economic Review, 93(1): 170-192.

Anderson, James E., and J. Peter Neary. 2005. Measuring the Restrictiveness of International Trade Policy. Vol. 1 of MIT Press Books, The MIT Press.

Anderson, James E., and Yoto V. Yotov. 2016. "Terms of Trade and Global Efficiency Effects of Free Trade Agreements, 1990-2002." Journal of International Economics, 99(C): 279-298.

Anderson, James, Mario Larch, and Yoto V. Yotov. 2015. "Estimating General Equilibrium Trade Policy Effects: GE PPML." CESifo Working Paper No. 5592.

Anderson, J.E. 2011. "The Gravity Model." Annual Review of Economics, 3: 133-160.

Anderson, J.E., and E. van Wincoop. 2004. "Trade Costs." Journal of Economic Literature, 42(3): 691-751.

Anderson, J.E., and Yoto V. Yotov. 2010. "Specialization: Pro- and Anti-Globalizing, 1990-2002." NBER Working Paper No. 16301.

Anderson, J.E., and Yoto V. Yotov. 2011. "Terms of Trade and Global Efficiency Effects of Free Trade Agreements, 1990-2002." NBER Working Paper No. 17003.

Anderson, J.E., Ingo Borchert, Aaditya Mattoo, and Yoto V. Yotov. 2015. "Modeling Services Trade, Trade Costs, Borders and Output." Manuscript.

Anderson, J.E., Mario Larch, Dennis Novy, and Yoto V. Yotov. 2014. "Internal Trade Costs." Manuscript.

Anderson, J.E., Mykyta Vesselovsky, and Yoto V. Yotov. 2016. "Gravity with Scale Economies." Journal of International Economics, 100: 174-193.

Arkolakis, Costas, Arnaud Costinot, and Andrés Rodríguez-Clare. 2012. "New Trade Models, Same Old Gains?" American Economic Review, 102(1): 94-130. 
Armington, P.S. 1969. "A Theory of Demand for Products Distinguished by Place of Production." IMF Staff Papers, 16: 159-176.

Arvis, Jean-Francois, and Ben Shepherd. 2013. "The Poisson Quasi-Maximum Likelihood Estimator: A Solution to the "Adding up" Problem in Gravity Models." Applied Economics Letters, 20(6): 515-519.

Baier, Scott L., and Jeffrey H. Bergstrand. 2002. "On the Endogeneity of International Trade Flows and Free Trade Agreements." unpublished manuscript, available for download at http://www3.nd.edu/ j jbergstr/working_papers.html.

Baier, Scott L., and Jeffrey H. Bergstrand. 2004. "The Economic Determinants of Free Trade Agreements." Journal of International Economics, 64(1): 29-63.

Baier, Scott L., and Jeffrey H. Bergstrand. 2007. "Do Free Trade Agreements Actually Increase Members' International Trade?" Journal of International Economics, 71(1): 7295.

Baier, Scott L., and Jeffrey H. Bergstrand. 2009. "Estimating the Effects of Free Trade Agreements on International Trade Flows using Matching Econometrics." Journal of International Economics, 77(1): 63-76.

Baier, Scott L., Yoto V. Yotov, and Thomas Zylkin. 2016. "On the Widely Differing Effects of Free Trade Agreements: Lessons from Twenty Years of Trade Integration." Manuscript.

Baldwin, R.E., and D. Taglioni. 2006. "Gravity for Dummies and Dummies for Gravity Equations." NBER Working Paper No. 12516.

Bergstrand, Jeffrey H., Mario Larch, and Yoto V. Yotov. 2015. "Economic Integration Agreements, Border Effects, and Distance Elasticities in the Gravity Equation." European Economic Review, 78: 307-327.

Bergstrand, J.H. 1985. "The Gravity Equation in International Trade: Some Microeconomic Foundations and Empirical Evidence." Review of Economics and Statistics, 67(3): 474-481.

Bergstrand, J.H. 1989. "The Generalized Gravity Equation, Monopolistic Competition, and the Factor-Proportions Theory of Trade." Review of Economics and Statistics, 71(1): 143-53.

Borchert, Ingo, and Yoto V. Yotov. 2016. "Globalization and International Trade." Manuscript.

Borchert, Ingo, Batshur Gootiiz, and Aaditya Mattoo. 2012. "Guide to the Services Trade Restrictions Database." The World Bank Policy Research Working Paper Series.

Bouet, A., Y. Decreux, L. Fontagne, S. Jean, and D. Laborde. 2005. "A Consistent, Ad-Valorem Equivalent Measrue of Applied Protection Across the World: the MacMap HS6 Database." CEPII Working Paper No. 2004-22. 
Boulhol, Hervé, and Alain de Serres. 2010. "Have Developed Countries Escaped the Curse of Distance?" Journal of Economic Geography, 10(1): 113-139.

Broda, C., J. Greenfield, and D. Weinstein. 2006. "From Groundnuts to Globalization: A Structural Estimate of Trade and Growth." NBER Working Paper No. 12512.

Brun, Jean-François, Céline Carrère, Patrick Guillaumont, and Jaime de Melo. 2005. "Has Distance Died? Evidence from a Panel Gravity Model." World Bank Economic Review, 19(1): 99-120.

Buch, Claudia M., Jorn Kleinert, and Farid Toubal. 2004. "The Distance Puzzle: On the Interpretation of the Distance Coefficient in Gravity Equations." Economics Letters, 83(3): 293-298.

Caliendo, Lorenzo, and Fernando Parro. 2015. "Estimates of the Trade and Welfare Effects of NAFTA." Review of Economic Studies, 82(1): 1-44.

Carrère, Céline, and Maurice Schiff. 2005. "On the Geography of Trade. Distance is Alive and Well." Revue économique, 56(6): 1249-1274.

Chaney, Thomas. 2008. "Distorted Gravity: The Intensive and Extensive Margins of International Trade." American Economic Review, 98(4): 1707-1721.

Cheng, I-Hui, and Howard J. Wall. 2005. "Controlling for Heterogeneity in Gravity Models of Trade and Integration." Federal Reserve Bank of St. Louis Review, 87(1): 4963.

Coe, D., A. Subramanian, N. Tamirisa, and R. Bhavnani. 2002. "The Missing Globalization Puzzle." IMF Working Paper No. 171.

Costinot, Arnaud, and Andrés Rodríguez-Clare. 2014. "Trade Theory with Numbers: Quantifying the Consequences of Globalization." Chapter 4 in the Handbook of International Economics Vol. 4, eds. Gita Gopinath, Elhanan Helpman, and Kenneth S. Rogoff, Elsevier Ltd., Oxford.

Dai, Mian, Yoto V. Yotov, and Thomas Zylkin. 2014. "On the Trade-diversion Effects of Free Trade Agreements." Economics Letters, 122(2): 321-325.

Deardorff, Alan. 1998. "Determinants of Bilateral Trade: Does Gravity Work in a Neoclassical World?" In The Regionalization of the World Economy. NBER Chapters, 7-32. National Bureau of Economic Research, Inc.

Disdier, A.-C., and K. Head. 2008. "The Puzzling Persistence of the Distance Effect on Bilateral Trade." Review of Economics and Statistics, 90(1): 37-48.

Donaldson, Dave. 2016. "Railroads of the Raj: Estimating the Impact of Transportation Infrastructure." American Economic Review, forthcoming, available for download at http://economics.mit.edu/faculty/ddonald/publications. 
Eaton, Jonathan, and Akiko Tamura. 1995. "Bilateralism and Regionalism in Japanese and U.S. Trade and Direct Foreign Investment Patterns." NBER Working Paper No. 4758.

Eaton, Jonathan, and Samuel Kortum. 2002. "Technology, Geography and Trade." Econometrica, 70(5): 1741-1779.

Egger, Peter, and Kevin Staub. 2014. "GLM Estimation of Trade Gravity Models with Fixed Effects." unpublished manuscript.

Egger, Peter, and Mario Larch. 2012. "Tariff Evasion Effects in Quantitative General Equilibrium." Economics Letters, 116(2): 262-264.

Egger, Peter, and Sergey Nigai. 2015. "Structural Gravity with Dummies Only." CEPR Discussion Paper No. DP1042\%.

Egger, Peter, Mario Larch, Kevin E. Staub, and Rainer Winkelmann. 2011. "The Trade Effects of Endogenous Preferential Trade Agreements." American Economic Journal: Economic Policy, 3(3): 113-143.

Fally, Thibault. 2015. "Structural Gravity and Fixed Effects." Journal of International Economics, forthcoming, doi:10.1016/j.jinteco.2015.05.005.

Feenstra, R., and J. Romalis. 2014. "International Prices and Endogenous Quality." The Quarterly Journal of Economics, 129(2): 477-527.

Feenstra, R.C. 2004. Advanced International Trade: Theory and Evidence. Princeton, New Jersey:Princeton University Press.

Francois, J., and O. Pindyuk. 2013. "Consolidated Data on International Trade in Services." Rotterdam, Institute for International and Development Economics, IIDE Discussion Paper 20130101.

Genereux, P.A., and B. Langen. 2002. "The Derivation of Provincial (inter-regional) Trade Flows: The Canadian Experience." Statistics Canada Working Paper.

Handley, K. 2014. "Exporting Under Trade Policy Uncertainty: Theory and Evidence." Journal of International Economics, 94(1): 50-66.

Handley, K., and N. Limao. 2013. "Policy Uncertainty, Trade and Welfare: Theory and Evidence for China and the U.S." NBER Working Paper No. 19376.

Head, K., and J. Ries. 2001. "Increasing Returns Versus National Product Differentiation as an Explanation for the Pattern of U.S.-Canada Trade." American Economic Review, 91(4): 858-876.

Head, Keith, and Thierry Mayer. 2013. "What Separates Us? Sources of Resistance to Globalization." Canadian Journal of Economics, 46(4): 1196-1231. 
Head, Keith, and Thierry Mayer. 2014. "Gravity Equations: Workhorse, Toolkit, and Cookbook." Chapter 3 in the Handbook of International Economics Vol. 4, eds. Gita Gopinath, Elhanan Helpman, and Kenneth S. Rogoff, Elsevier Ltd., Oxford.

Head, K., T. Mayer, and J. Ries. 2010. "The Erosion of Colonial Trade Linkages after Independence." Journal of International Economics, 81(1): 1-14.

Heid, Benedikt, and Mario Larch. 2016. "Gravity with Unemployment." Journal of International Economics, 101: 70-85.

Heid, Benedikt, Mario Larch, and Yoto V. Yotov. 2015. "A Simple Method to Estimate the Effects of Non-discriminatory Trade Policy within Structural Gravity Models." Manuscript.

Helpman, Elhanan, Marc Melitz, and Yona Rubinstein. 2008. "Trading Partners and Trading Volumes." Quarterly Journal of Economics, 123(2): 441-487.

Horn, H., P.C. Mavroidis, and E. Wijkström. 2012. "Between Transparency and Adjudication: Environmental Measures in the WTO TBT Committee." Stockholm, Entwined, Issue Brief No.12.

Hummels, D. 2001. "Toward a Geography of Trade Costs." unpublished manuscript, available for download at http://www.krannert.purdue.edu/faculty/hummelsd/research /toward/TGTC.pdf.

Krugman, P.R. 1980. "Scale Economies, Product Differentiation, and the Pattern of Trade." American Economic Review, 70(5): 950-959.

Larch, Mario, and Joschka Wanner. 2014. "Carbon Tariffs: An Analysis of the Trade, Welfare and Emission Effects." CESifo Working Paper No. 4598.

Larch, Mario, and Yoto Yotov. 2016. "General Equilibrium Trade Policy Analysis with Structural Gravity." Manuscript.

Larch, Mario, Pehr-Johan Norbäck, Steffen Sirries, and Dieter Urban. 2016. "Heterogeneous Firms, Globalization and the Distance Puzzle." 2016, The World Economy, forthcoming.

Lin, Faqin, and Nicholas C.S. Sim. 2012. "Death of Distance and the Distance Puzzle." Economics Letters, 116(2): 225-228.

Magee, C.S. 2003. "Endogenous Preferential Trade Agreements: An Empirical Analysis." Contributions to Economic Analysis \& Policy, 2: Articel 15.

Martin, W., and C.S. Pham. 2008. "Estimating the Gravity Equation when Zero Trade Flows are Frequent." Working Paper No. 2008-03. Deakin University, School of Accounting, Economics and Finance.

Mayer, T., and S. Zignago. 2011. "Notes on CEPII's Distances Measures: the GeoDist Database." CEPII Working Paper No. 2011-25. 
McCallum, John. 1995. "National Borders Matter." American Economic Review, 85(3): 615-623.

Melitz, Jacques. 2008. "Language and Foreign Trade." European Economic Review, 52(4): 667-699.

Melitz, Jacques, and Farid Toubal. 2014. "Native Language, Spoken Language, Translation and Trade." Journal of International Economics, 93(2): 351-363.

Nicita, A., and M. Olarreaga. 2007. "Trade, Production and Protection 1976-2004." World Bank Economic Review, 21(1): 165-171.

Novy, Dennis. 2013a. "Gravity Redux: Measuring International Trade Costs With Panel Data." Economic Inquiry, 51(1): 101-121.

Novy, Dennis. 2013b. "International Trade without CES: Estimating Translog Gravity." Journal of International Economics, 89(2): 271-282.

Olivero, María Pía, and Yoto V. Yotov. 2012. "Dynamic Gravity: Endogenous Country Size and Asset Accumulation." Canadian Journal of Economics, 45(1): 64-92.

Osnago, A., R. Piermartini, and N. Rocha. 2015. "Trade Policy Uncertainty As Barrier to Trade." WTO Working Paper ERSD-2015-05.

Ramondo, Natalia, Andres Rodríguez-Clare, and S. Saborío-Rodríguez. 2014. "Trade, Domestic Frictions, and Scale Effects." Working Paper.

Redding, S., and A. Venables. 2004. "Economic Geography and International Inequality." Journal of International Economic, 62(1): 53-82.

Romalis, John. 2007. "NAFTA's and CUSTFA's Impact on International Trade." Review of Economics and Statistics, 89(3): 416-435.

Santos Silva, J.M.C., and Silvana Tenreyro. 2006. "The Log of Gravity." Review of Economics and Statistics, 88(4): 641-658.

Santos Silva, J.M.C., and Silvana Tenreyro. 2011. "Further Simulation Evidence on the Performance of the Poisson Pseudo-Maximum Likelihood Estimator." Economics Letters, 112(2): 220-222.

Tinbergen, Jan. 1962. Shaping the World Economy: Suggestions for an International Economic Policy. New York:The Twentieth Century Fund.

Trefler, Daniel. 1993. "Trade Liberalization and the Theory of Endogeneous Protection: An Econometric Study of U.S. Import Policy." Journal of Political Economy, 101(1): 138-160.

Trefler, Daniel. 2004. "The Long and Short of the Canada-U.S. Free Trade Agreement." American Economic Review, 94(4): 870-895.

UNCTAD-WTO. 2012. "A Practical Guide to Trade Policy Analysis.” Geneva: WTO. 
Wei, Shang-Jin. 1996. "Intra-National versus International Trade: How Stubborn are Nations in Global Integration?" NBER Working Papers No 5531.

Wooldridge, Jeffrey M. 2010. Econometric Analysis of Cross Section and Panel Data. . 2nd ed., Cambridge, Massachusetts:The MIT Press.

WTO. 2012. "World Trade Report 2012. Trade and Public Policies: a Closer Look at Non - Tariff Measures in the 21st Century." Geneva: WTO.

WTO. 2015. "World Trade Report 2015. Speeding Up Trade: the Benefits and the Challenges of Implementing the WTO Trade Facilitation Agreement." Geneva: WTO.

Yotov, Yoto V. 2012. "A Simple Solution to the Distance Puzzle in International Trade." Economics Letters, 117(3): 794-798. 
Table 1: Traditional Gravity Estimates

\begin{tabular}{|c|c|c|c|c|}
\hline & $\begin{array}{c}(1) \\
\text { OLS }\end{array}$ & $\begin{array}{c}(2) \\
\text { RMTNS }\end{array}$ & $\begin{array}{c}(3) \\
\text { FES }\end{array}$ & $\begin{array}{c}(4) \\
\text { PPML }\end{array}$ \\
\hline ln_DIST & $\begin{array}{c}-1.002 \\
(0.027)^{* *}\end{array}$ & $\begin{array}{c}-1.162 \\
(0.036)^{* *}\end{array}$ & $\begin{array}{c}-1.216 \\
(0.038)^{* *}\end{array}$ & $\begin{array}{c}-0.841 \\
(0.032)^{* *}\end{array}$ \\
\hline CNTG & $\begin{array}{c}0.574 \\
(0.185)^{* *}\end{array}$ & $\begin{array}{c}0.307 \\
(0.176)^{+}\end{array}$ & $\begin{array}{c}0.223 \\
(0.203)\end{array}$ & $\begin{array}{c}0.437 \\
(0.083)^{* *}\end{array}$ \\
\hline LANG & $\begin{array}{c}0.802 \\
(0.082)^{* *}\end{array}$ & $\begin{array}{c}0.666 \\
(0.082)^{* *}\end{array}$ & $\begin{array}{c}0.661 \\
(0.082)^{* *}\end{array}$ & $\begin{array}{c}0.247 \\
(0.077)^{* *}\end{array}$ \\
\hline CLNY & $\begin{array}{c}0.735 \\
(0.144)^{* *}\end{array}$ & $\begin{array}{c}0.867 \\
(0.148)^{* *}\end{array}$ & $\begin{array}{c}0.670 \\
(0.149)^{* *}\end{array}$ & $\begin{array}{c}-0.222 \\
(0.116)^{+}\end{array}$ \\
\hline ln_OUTPUT & $\begin{array}{c}1.190 \\
(0.009)^{* *}\end{array}$ & $\begin{array}{c}1.208 \\
(0.010)^{* *}\end{array}$ & & \\
\hline ln_EXPEND & $\begin{array}{c}0.908 \\
(0.010)^{* *}\end{array}$ & $\begin{array}{c}0.928 \\
(0.010)^{* *}\end{array}$ & & \\
\hline REM_EXP & & $\begin{array}{c}0.600 \\
(0.094)^{* *}\end{array}$ & & \\
\hline REM_IMP & & $\begin{array}{c}0.623 \\
(0.103)^{* *}\end{array}$ & & \\
\hline CONSTANT & $\begin{array}{c}-11.283 \\
(0.296)^{* *}\end{array}$ & $\begin{array}{c}-21.222 \\
(1.419)^{* *}\end{array}$ & $\begin{array}{c}1.719 \\
(0.715)^{*}\end{array}$ & $\begin{array}{c}14.139 \\
(0.391)^{* *}\end{array}$ \\
\hline$N$ & 25689 & 25689 & 25689 & 28152 \\
\hline$R^{2}$ & 0.759 & 0.761 & 0.843 & 0.614 \\
\hline$i, t \mathrm{FEs}$ & No & No & Yes & Yes \\
\hline$j, t \mathrm{FEs}$ & No & No & Yes & Yes \\
\hline RESET p-vals & 0.000 & 0.000 & 0.000 & 0.642 \\
\hline
\end{tabular}

Notes: This table reports a series of gravity estimation results. All estimates are obtained with data for the years 1986, 1990, 1994, 1998, 2002, and 2006. Columns (1)-(3) use the OLS estimator. Column (1) does not control for the multilateral resistances (MRs). Column (2) uses 'remoteness indexes' to control for the MRs. Column (3) uses importer-time and exporter-time fixed effects, whose estimates are omitted for brevity, to control for the MRs. Finally, column (4) employs the PPML estimator. Standard errors are clustered by country pair and are reported in in parentheses. ${ }^{+} p<0.10$, ${ }^{*} p<.05,{ }^{* *} p<.01$. See text for further details. 
Figure 1: Domestic vs. International Costs

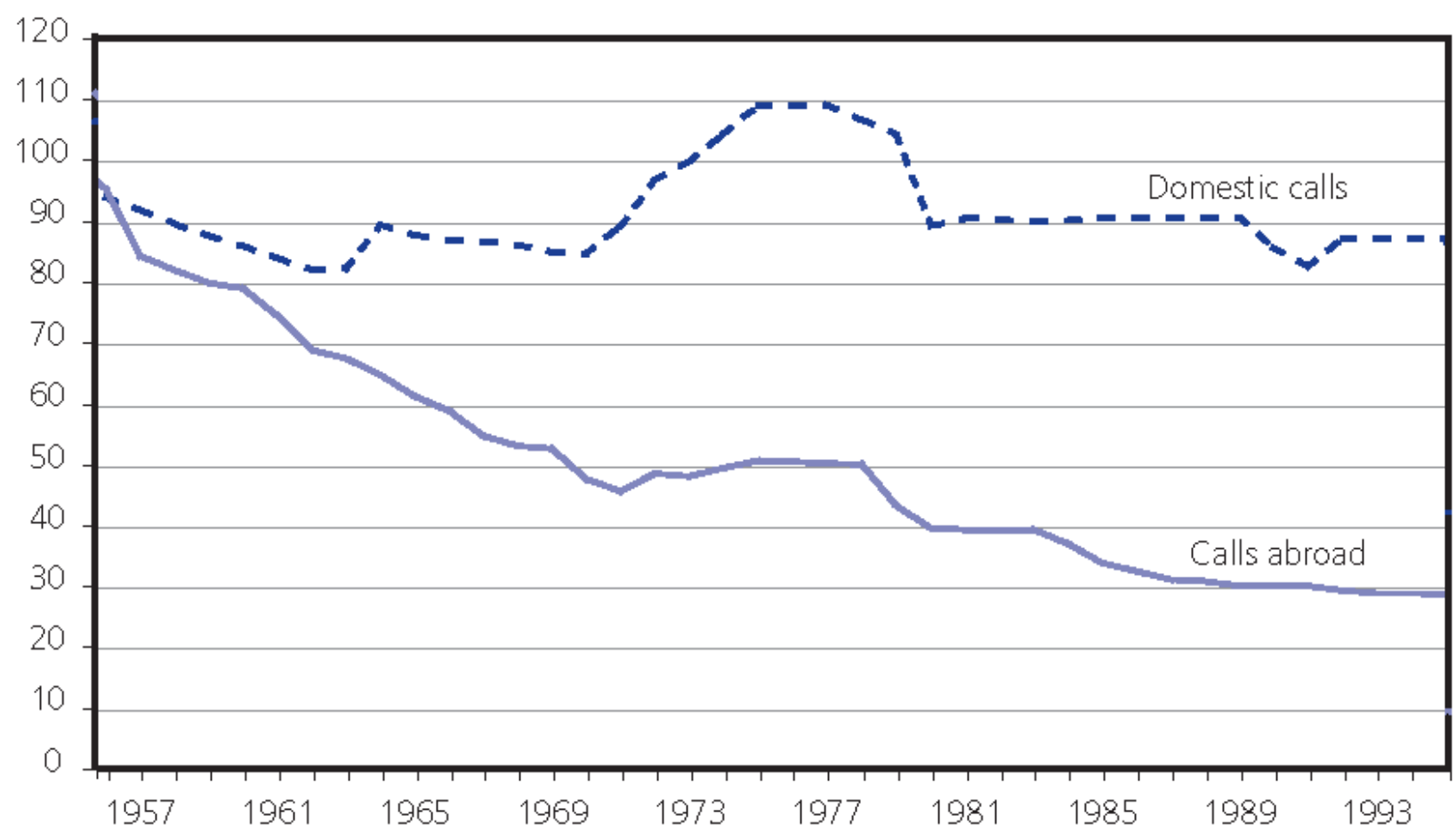

This figure replicates Figure 1 from Borchert and Yotov (2016). The graph is extracted from Chart 11 at page 87 of the World Trade Report 2008, which covers the years 1949-2005. 
Table 2: A Simple Solution to the Distance Puzzle In Trade

\begin{tabular}{|c|c|c|c|c|c|}
\hline & $\begin{array}{c}(1) \\
\text { OLS }\end{array}$ & $\begin{array}{c}(2) \\
\text { PPML }\end{array}$ & $\begin{array}{c}(3) \\
\text { INTRA }\end{array}$ & $\begin{array}{c}(4) \\
\text { BRDR }\end{array}$ & $\begin{array}{c}(5) \\
\text { FEs }\end{array}$ \\
\hline ln_DIST_1986 & $\begin{array}{c}-1.168 \\
(0.044)^{* *}\end{array}$ & $\begin{array}{c}-0.859 \\
(0.037)^{* *}\end{array}$ & $\begin{array}{c}-0.980 \\
(0.072)^{* *}\end{array}$ & $\begin{array}{c}-0.857 \\
(0.063)^{* *}\end{array}$ & $\begin{array}{c}-0.910 \\
(0.032)^{* *}\end{array}$ \\
\hline ln_DIST_1990 & $\begin{array}{c}-1.155 \\
(0.042)^{* *}\end{array}$ & $\begin{array}{c}-0.834 \\
(0.038)^{* *}\end{array}$ & $\begin{array}{c}-0.940 \\
(0.073)^{* *}\end{array}$ & $\begin{array}{c}-0.819 \\
(0.063)^{* *}\end{array}$ & $\begin{array}{c}-0.879 \\
(0.032)^{* *}\end{array}$ \\
\hline ln_DIST_1994 & $\begin{array}{c}-1.211 \\
(0.046)^{* *}\end{array}$ & $\begin{array}{c}-0.835 \\
(0.035)^{* *}\end{array}$ & $\begin{array}{c}-0.915 \\
(0.072)^{* *}\end{array}$ & $\begin{array}{c}-0.796 \\
(0.063)^{* *}\end{array}$ & $\begin{array}{c}-0.860 \\
(0.032)^{* *}\end{array}$ \\
\hline ln_DIST_1998 & $\begin{array}{c}-1.248 \\
(0.043)^{* *}\end{array}$ & $\begin{array}{c}-0.847 \\
(0.035)^{* *}\end{array}$ & $\begin{array}{c}-0.887 \\
(0.071)^{* *}\end{array}$ & $\begin{array}{c}-0.770 \\
(0.063)^{* *}\end{array}$ & $\begin{array}{c}-0.833 \\
(0.032)^{* *}\end{array}$ \\
\hline ln_DIST_2002 & $\begin{array}{c}-1.241 \\
(0.044)^{* *}\end{array}$ & $\begin{array}{c}-0.848 \\
(0.032)^{* *}\end{array}$ & $\begin{array}{c}-0.884 \\
(0.071)^{* *}\end{array}$ & $\begin{array}{c}-0.767 \\
(0.063)^{* *}\end{array}$ & $\begin{array}{c}-0.829 \\
(0.032)^{* *}\end{array}$ \\
\hline ln_DIST_2006 & $\begin{array}{c}-1.261 \\
(0.044)^{* *}\end{array}$ & $\begin{array}{c}-0.836 \\
(0.031)^{* *}\end{array}$ & $\begin{array}{c}-0.872 \\
(0.071)^{* *}\end{array}$ & $\begin{array}{c}-0.754 \\
(0.062)^{* *}\end{array}$ & $\begin{array}{c}-0.811 \\
(0.032)^{* *}\end{array}$ \\
\hline CNTG & $\begin{array}{c}0.223 \\
(0.203)\end{array}$ & $\begin{array}{c}0.437 \\
(0.083)^{* *}\end{array}$ & $\begin{array}{c}0.371 \\
(0.140)^{* *}\end{array}$ & $\begin{array}{c}0.574 \\
(0.155)^{* *}\end{array}$ & $\begin{array}{c}0.442 \\
(0.082)^{* *}\end{array}$ \\
\hline LANG & $\begin{array}{c}0.661 \\
(0.082)^{* *}\end{array}$ & $\begin{array}{c}0.248 \\
(0.077)^{* *}\end{array}$ & $\begin{array}{c}0.337 \\
(0.168)^{*}\end{array}$ & $\begin{array}{c}0.352 \\
(0.137)^{*}\end{array}$ & $\begin{array}{c}0.241 \\
(0.076)^{* *}\end{array}$ \\
\hline CLNY & $\begin{array}{c}0.670 \\
(0.149)^{* *}\end{array}$ & $\begin{array}{c}-0.222 \\
(0.116)^{+}\end{array}$ & $\begin{array}{c}0.019 \\
(0.156)\end{array}$ & $\begin{array}{c}0.027 \\
(0.125)\end{array}$ & $\begin{array}{c}-0.220 \\
(0.117)^{+}\end{array}$ \\
\hline ln_DIST_INTRA & & & $\begin{array}{c}-0.488 \\
(0.101)^{* *}\end{array}$ & $\begin{array}{c}-0.602 \\
(0.109)^{* *}\end{array}$ & \\
\hline SMCTRY & & & & $\begin{array}{c}1.689 \\
(0.574)^{* *}\end{array}$ & \\
\hline$N$ & 25689 & 28152 & 28566 & 28566 & 28566 \\
\hline$\% \Delta l n \_D I S T_{1986-2006}$ & $\begin{array}{c}7.950 \\
(3.759)^{*}\end{array}$ & $\begin{array}{l}-2.750 \\
(3.004)\end{array}$ & $\begin{array}{c}-10.965 \\
(1.058)^{* *}\end{array}$ & $\begin{array}{c}-11.969 \\
(1.173)^{* *}\end{array}$ & $\begin{array}{c}-10.931 \\
(0.769)^{* *}\end{array}$ \\
\hline
\end{tabular}

Notes: This table reports estimation results related to the 'distance puzzle' in international trade. All estimates are obtained with data for the years 1986, 1990, 1994, 1998, 2002, and 2006, and use exporter-time and importer-time fixed effects. The estimates of the fixed effects are omitted for brevity. Columns (1) and (2) use data on international trade flows only. Column (1) employs the OLS estimator and column (2) uses the PPML estimator. Column (3) adds internal trade observations and uses intra-national distance as an additional covariate. Column (4) adds an indicator covariate for international trade. Finally, column (5) uses country-specific dummies for intra-national trade. The bottom panel of the table reports the percentage change in the estimates of the effects of bilateral distance between 1986 and 2006. Standard errors are clustered by country pair and are reported in in parentheses. ${ }^{+} p<0.10,{ }^{*}$ $p<.05,{ }^{* *} p<.01$. See text for further details. 
Table 3: Estimating The Effects of Regional Trade Agreements

\begin{tabular}{|c|c|c|c|c|c|c|c|}
\hline & $\begin{array}{c}(1) \\
\text { OLS }\end{array}$ & $\begin{array}{c}(2) \\
\text { PPML }\end{array}$ & $\begin{array}{c}(3) \\
\text { INTRA }\end{array}$ & $\begin{array}{c}(4) \\
\text { ENDG }\end{array}$ & $\begin{array}{c}(5) \\
\text { LEAD }\end{array}$ & $\begin{array}{c}(6) \\
\text { PHSNG }\end{array}$ & $\begin{array}{c}(7) \\
\text { GLBZN }\end{array}$ \\
\hline $\ln _{-}$DIST & $\begin{array}{c}-1.216 \\
(0.039)^{* *}\end{array}$ & $\begin{array}{c}-0.822 \\
(0.031)^{* *}\end{array}$ & $\begin{array}{c}-0.800 \\
(0.030)^{* *}\end{array}$ & & & & \\
\hline CNTG & $\begin{array}{c}0.223 \\
(0.203)\end{array}$ & $\begin{array}{c}0.416 \\
(0.083)^{* *}\end{array}$ & $\begin{array}{c}0.393 \\
(0.079)^{* *}\end{array}$ & & & & \\
\hline LANG & $\begin{array}{c}0.661 \\
(0.082)^{* *}\end{array}$ & $\begin{array}{c}0.250 \\
(0.077)^{* *}\end{array}$ & $\begin{array}{c}0.244 \\
(0.077)^{* *}\end{array}$ & & & & \\
\hline CLNY & $\begin{array}{c}0.670 \\
(0.149)^{* *}\end{array}$ & $\begin{array}{c}-0.205 \\
(0.114)^{+}\end{array}$ & $\begin{array}{l}-0.182 \\
(0.113)\end{array}$ & & & & \\
\hline RTA & $\begin{array}{l}-0.004 \\
(0.054)\end{array}$ & $\begin{array}{c}0.191 \\
(0.066)^{* *}\end{array}$ & $\begin{array}{c}0.409 \\
(0.069)^{* *}\end{array}$ & $\begin{array}{c}0.557 \\
(0.102)^{* *}\end{array}$ & $\begin{array}{c}0.520 \\
(0.086)^{* *}\end{array}$ & $\begin{array}{c}0.291 \\
(0.089)^{* *}\end{array}$ & $\begin{array}{c}0.116 \\
(0.087)\end{array}$ \\
\hline RTA_LEAD4 & & & & & $\begin{array}{c}0.077 \\
(0.092)\end{array}$ & & \\
\hline RTA_LAG4 & & & & & & $\begin{array}{c}0.414 \\
(0.067)^{* *}\end{array}$ & $\begin{array}{c}0.288 \\
(0.062)^{* *}\end{array}$ \\
\hline RTA_LAG8 & & & & & & $\begin{array}{c}0.169 \\
(0.043)^{* *}\end{array}$ & $\begin{array}{c}0.069 \\
(0.048)\end{array}$ \\
\hline RTA_LAG12 & & & & & & $\begin{array}{c}0.119 \\
(0.030)^{* *}\end{array}$ & $\begin{array}{c}0.002 \\
(0.029)\end{array}$ \\
\hline INTL_BRDR_1986 & & & & & & & $\begin{array}{c}-0.706 \\
(0.048)^{* *}\end{array}$ \\
\hline INTL_BRDR_1990 & & & & & & & $\begin{array}{c}-0.480 \\
(0.043)^{* *}\end{array}$ \\
\hline INTL_BRDR_1994 & & & & & & & $\begin{array}{c}-0.367 \\
(0.033)^{* *}\end{array}$ \\
\hline INTL_BRDR_1998 & & & & & & & $\begin{array}{c}-0.158 \\
(0.023)^{* *}\end{array}$ \\
\hline INTL_BRDR_2002 & & & & & & & $\begin{array}{c}-0.141 \\
(0.017)^{* *}\end{array}$ \\
\hline Total RTA Effects & & & & & & $\begin{array}{c}0.992 \\
(0.094)^{* *}\end{array}$ & $\begin{array}{c}0.475 \\
(0.109)^{* *}\end{array}$ \\
\hline$N$ & 25689 & 28152 & 28566 & 28482 & 28482 & 28482 & 28482 \\
\hline
\end{tabular}

Notes: This table reports estimates of the effects of RTAs. All estimates are obtained with data for the years 1986, 1990, 1994, 1998, 2002, and 2006, and use exporter-time and importer-time fixed effects. The estimates of the fixed effects are omitted for brevity. Columns (1) and (2) use data on international trade flows only. Column (1) employs the OLS estimator and column (2) uses the PPML estimator. Column (3) adds intra-national trade observations and uses country-specific dummies for internal trade. Column (4) adds pair fixed effects. The estimates of the pair fixed effects are omitted for brevity. Column (5) introduces RTA lead. Column (6) allows for phasing-in effects of RTAs. Finally, column (7) accounts for the effects of globalization. Standard errors are clustered by country pair and are reported in in parentheses. ${ }^{+} p<0.10,{ }^{*} p<.05,{ }^{* *} p<.01$. See text for further details. 
Table 4: Non-discriminatory Trade Policy Effects

\begin{tabular}{lcc}
\hline \hline & $(1)$ & $(2)$ \\
& RTAs & TARIFFS \\
\hline RTA & 0.375 & -0.148 \\
& $(0.078)^{* *}$ & $(0.072)^{*}$ \\
RTA_LAG3 & 0.246 & 0.249 \\
& $(0.051)^{* *}$ & $(0.049)^{* *}$ \\
RTA_LAG6 & 0.249 & 0.265 \\
& $(0.054)^{* *}$ & $(0.048)^{* *}$ \\
RTA_LAG9 & 0.085 & 0.102 \\
& $(0.042)^{*}$ & $(0.043)^{*}$ \\
ln_MFN_TARIFF & & -6.673 \\
& & $(0.669)^{* *}$ \\
\hline$N$ & 18928 & 18928 \\
\hline \hline
\end{tabular}

Notes: This table reports estimates of the effects of RTAs and MFN tariffs. All estimates are obtained with data for the years 1988, 1991, 1994, 1997, 2000, 2003, and 2006. All specifications use exporter-time, importer-time, and pair fixed effects. The estimates of the fixed effects are omitted for brevity. Column (1) estimates the phasing-in effects of RTAs. Column (2) introduces MFN tariffs. Standard errors are clustered by country pair and are reported in parentheses. ${ }^{+} p<0.10$, * $p<.05,{ }^{* *} p<.01$. See text for further details. 


\section{Appendix A: Structural Gravity with Tariffs}

This appendix extends the standard gravity model to accommodate tariffs and tariff revenues. See for a similar derivation Heid and Larch (2016), and for an application of such a framework to quantify tariff evasion Egger and Larch (2012). All main assumptions are preserved. Specifically, each of the $N$ countries in the world produces a differentiated variety of goods (Armington, 1969). The supply of each variety is fixed at $Q_{i}$ with a corresponding factorygate price $p_{i}$. Thus, the value of (income from) domestic production in country $i$ is defined as $Y_{i}=p_{i} Q_{i}$. Consumer preferences are CES:

$$
\left\{\sum_{i} \beta_{i}^{\frac{1-\sigma}{\sigma}} c_{i j}\right\}^{\frac{\sigma-1}{\sigma}}
$$

where $\sigma>1$ is the trade elasticity of substitution; $\beta_{i}>0$ is the CES preference parameter; and $c_{i j}$ denotes consumption of varieties from country $i$ in country $j$. Consumers maximize (33) subject to the following budget constraint:

$$
\sum_{i} p_{i j} c_{i j}=Y_{j}+\sum_{i}\left(\tau_{i j}-1\right) X_{i j} / \tau_{i j}
$$

Budget constraint (34) is adjusted to reflect the fact that tariff revenues, $\sum_{i}\left(\tau_{i j}-1\right) X_{i j} / \tau_{i j}$, are collected, and that these revenues are assumed to be fully rebated to consumers and add to their nominal income from production $Y_{j}$. Tariffs here are defined as $\tau_{i j}=1+a d v \_t a r i f f_{i j}$, where $a d v \_$tariff $f_{i j}$ is the ad-valorem tariff on varieties imported in country $j$ from country $i$. The term $\bar{\tau}_{i j}$ appears in the denominator of the tariff revenue component because tariffs are imposed on the pre-tariff value of imports. Finally, (34) ensures that the total expenditure in country $j$ is equal to the total spending on varieties from all countries, including $j$, at delivered prices $p_{i j}=\tau_{i j} p_{i} t_{i j}$, which now are defined as a function of tariffs, $\tau_{i j}$, in addition to factory-gate prices in the origin, $p_{i}$, and the iceberg costs, $t_{i j} \geq 1$.

Let $E_{j}$ denote total expenditure in $j$ and solve the consumer's optimization problem to obtain the Marshallian consumer demand for goods shipped from origin $i$ to destination $j$ :

$$
c_{i j}=p_{i j}^{-\sigma}\left(\frac{\beta_{i}}{P_{j}}\right)^{(1-\sigma)} E_{j},
$$

where, $P_{j}$ denotes the CES consumer price index:

$$
P_{j}=\left[\sum_{i}\left(\beta_{i} p_{i j}\right)^{1-\sigma}\right]^{1 /(1-\sigma)} .
$$

Use (35) to express the value of exports from $i$ to $j$ at delivered prices as:

$$
X_{i j}=c_{i j} \tau_{i j} p_{i} t_{i j}=\left(\frac{\beta_{i} \tau_{i j} p_{i} t_{i j}}{P_{j}}\right)^{(1-\sigma)} E_{j} .
$$


The final step in the derivation of the structural gravity model is to impose market clearance for goods from each origin:

$$
Y_{i}=\sum_{j} X_{i j} / \tau_{i j}=\sum_{j} \tau_{i j}^{-\sigma}\left(\frac{\beta_{i} p_{i} t_{i j}}{P_{j}}\right)^{1-\sigma} E_{j} .
$$

The first equality in (38) tells us that the pre-tariff value of total expenditure on goods from country $i, \sum_{j} X_{i j} / \tau_{i j}$, is equal to the value of output in $i, Y_{i}$. The second equality in (38) applies the definition of bilateral expenditure from equation (37). Define $Y \equiv \sum_{i} Y_{i}$, divide the left and the right side of (38), and rearrange terms to obtain:

$$
\left(\beta_{i} p_{i}\right)^{1-\sigma}=\frac{Y_{i} / Y}{\sum_{j} \tau_{i j}^{-\sigma}\left(\frac{t_{i j}}{P_{j}}\right)^{1-\sigma} \frac{E_{j}}{Y}} .
$$

Define the term in the denominator of 39 as $\Pi_{i}^{1-\sigma} \equiv \sum_{j} \tau_{i j}^{-\sigma}\left(\frac{t_{i j}}{P_{j}}\right)^{1-\sigma} \frac{E_{j}}{Y}$, and substitute this definition into Equation (39):

$$
\left(\beta_{i} p_{i}\right)^{1-\sigma}=\frac{Y_{i} / Y}{\Pi_{i}^{1-\sigma}}
$$

Use (40) to substitute for the power transform $\left(\beta_{i} p_{i}\right)^{1-\sigma}$ in the bilateral allocations Equation (37) and in the CES price index Equation (36). Combine the definition of $\Pi_{i}^{1-\sigma}$ with the resulting expressions that correspond to Equation (37) and Equation (36) to obtain the structural gravity system with tariffs:

$$
\begin{aligned}
X_{i j} & =\frac{Y_{i} E_{j}}{Y}\left(\frac{t_{i j} \tau_{i j}}{\Pi_{i} P_{j}}\right)^{1-\sigma}, \\
\Pi_{i}^{1-\sigma} & =\sum_{j} \tau_{i j}^{-\sigma}\left(\frac{t_{i j}}{P_{j}}\right)^{1-\sigma} \frac{E_{j}}{Y} \\
P_{j}^{1-\sigma} & =\sum_{i}\left(\frac{t_{i j} \tau_{i j}}{\Pi_{i}}\right)^{1-\sigma} \frac{Y_{i}}{Y} .
\end{aligned}
$$

System (41)-(43) resembles system (1)-(3) from the main text. However, there are two differences, which have implications for the estimation of gravity and for the welfare analysis with the gravity model. These differences are:

1. Tariffs enter the gravity equation (41) directly and indirectly, via the multilateral resistances. This difference has implications for both gravity estimations and for welfare analysis. The implication with respect to gravity estimations is that tariffs will appear in the estimating equation and, more importantly, the estimate of the coefficient on tariffs can be used to directly recover a value for the trade elasticity parameter. In addition, the structural gravity theory presented here can be used to calculate tariff equivalent effects for each of the gravity covariates. We refer the reader to Larch and 
Wanner (2014) for further discussion and analysis of the empirical implications of the inclusion of tariffs.

2. We no longer have a simple expression for expenditure, which now differs from the value of total production owing to tariff revenues. This difference has no implications for gravity estimations since expenditure at the country level, regardless of their functional form, will be absorbed by the importer-time fixed effects. However, this difference has important implications for welfare analysis. Specifically, as demonstrated by Anderson and van Wincoop (2001), the expression for real income with rents from tariff becomes:

$$
\tilde{W}_{j}=\frac{Q_{j} p_{j}}{P_{j}} \frac{1}{1-\sum_{i}\left(\tau_{i j}-1\right) s_{i j} / \tau_{i j}},
$$

where $s_{i j}$ is the CES expenditure share on goods from country $i$ in country $j, s_{i j}=$ $X_{i j} / E_{j}=\left(\beta_{i} p_{i j} / P_{j}\right)^{1-\sigma}$. The first fraction in equation 44 is the expression for real income from the gravity model without tariffs. The second fraction is a tariff multiplier, which captures the additional welfare effects of the introduction of tariffs and rents. ${ }^{110}$ We refer the reader to Anderson and van Wincoop (2001) for further comparative statics and discussion of the welfare implications of the introduction of tariffs and rents.

\footnotetext{
${ }^{110}$ The expression for the tariff multiplier as an adjustment to nominal income can be obtained by using the definition of $s_{i j}$ in budget constraint (34) and then solving for total expenditure.
} 


\section{Appendix B: Data Bases and Data Sources Summary}

\begin{tabular}{|c|c|c|}
\hline Data & Database & Link \\
\hline \multirow{3}{*}{$\begin{array}{l}\text { Country-specific } \\
\text { data }\end{array}$} & IFS & http://data.imf.org/?sk=5DABAFF2-C5AD-4D27-A175-1253419C02D1 \\
\hline & WDIs & http://databank.worldbank.org/data/reports.aspx?source=world-development-indicators \\
\hline & PWT & http://www.rug.nl/research/ggdc/data/pwt \\
\hline \multirow{2}{*}{$\begin{array}{l}\text { Aggregated } \\
\text { merchandise } \\
\text { trade flows }\end{array}$} & DOTS & http://data.imf.org/?sk=9D6028D4-F14A-464C-A2F2-59B2CD424B85\&ss=13900303418545 \\
\hline & $\begin{array}{l}\text { Barbieri and Keshk's } \\
\text { Correlates of War } \\
\text { Project }\end{array}$ & http://correlatesofwar.org/data-sets/bilateral-trade. \\
\hline \multirow{5}{*}{$\begin{array}{l}\text { Disaggregated } \\
\text { merchandise } \\
\text { trade }\end{array}$} & Comtrade & http://comtrade.un.org \\
\hline & BACI & http://www.cepii.fr/cepii/en/bdd_modele/presentation.asp?id=1 \\
\hline & WTF & http://cid.econ.ucdavis.edu/Html/WTF_bilateral.html \\
\hline & Trade Map & http://www.trademap.org/Index.aspx \\
\hline & Global Trade Atlas & https://www.gtis.com/gta \\
\hline \multirow[t]{4}{*}{$\begin{array}{l}\text { Service } \\
\text { flows }\end{array}$} & $\begin{array}{lll}\text { OECD's } & \text { Trade } & \text { in } \\
\text { Services } & & \\
\end{array}$ & https://stats.oecd.org/Index.aspx?DataSetCode=TISP \\
\hline & UN Service Trade & http://unstats.un.org/unsd/servicetrade/sysLogin.aspx \\
\hline & Trade Map & http://www.trademap.org/Index.aspx \\
\hline & $\begin{array}{l}\text { Francois and Pindyuk's } \\
\text { Trade in Service }\end{array}$ & https://ideas.repec.org/p/lnz/wpaper/20130101.html \\
\hline $\begin{array}{l}\text { Agriculture trade } \\
\text { flows }\end{array}$ & $\begin{array}{ll}\text { FAOSTAT } & \text { Detailed } \\
\text { Trade Matrix } & \end{array}$ & http://faostat3.fao.org/download/T/TM/E \\
\hline \multirow[t]{3}{*}{$\begin{array}{l}\text { Intra-national } \\
\text { trade flows data }\end{array}$} & TPP & $\begin{array}{l}\text { http://econ.worldbank.org/WBSITE/EXTERNAL/EXTDEC/EXTRESEARCH/0„,contentMDK:21085384 pageP } \\
\text { K:64214825 piPK:64214943 theSitePK:469382,00.html }\end{array}$ \\
\hline & TradeProd & http://www.cepii.fr/CEPII/fr/bdd_modele/presentation.asp?id=5 \\
\hline & INDSTAT & http://stat.unido.org/ \\
\hline $\begin{array}{l}\text { Time-invariant } \\
\text { covariates }\end{array}$ & GeoDist & http://www.cepii.fr/cepii/en/bdd_modele/presentation.asp?id=6 \\
\hline \multirow[t]{3}{*}{ Tariff data } & IDB & https://tao.wto.org/welcome.aspx?ReturnUrl=\%2f\%3fui\%3d1\&ui=1 or http://tariffdata.wto.org/. \\
\hline & CTS & https://tao.wto.org/welcome.aspx?ReturnUrl=\%2f\%3fui\%3d1\&ui=1 or http://tariffdata.wto.org/. \\
\hline & TRAINS & $\begin{array}{l}\text { http://databank.worldbank.org/data/reports.aspx?source=UNCTAD- -Trade-Analysis-Information-System- } \\
\text { (TRAINS) }\end{array}$ \\
\hline
\end{tabular}




\begin{tabular}{|c|c|c|}
\hline & MacMap & http://www.macmap.org/Default.aspx?ReturnUrl=\%2fAdvancedSearch\%2fTariffAndTrade\%2fDefault.aspx \\
\hline & I-TIP & https://www.wto.org/english/res_e/statis_e/itip_e.htm \\
\hline & OECD's AMAD & https://www.oecd.org/site/amad. \\
\hline \multirow[t]{6}{*}{ Various NTMs } & TPP & $\begin{array}{l}\text { http://econ.worldbank.org/WBSITE/EXTERNAL/EXTDEC/EXTRESEARCH/0, contentMDK:21085384 pageP } \\
\text { K:64214825 piPK:64214943 theSitePK:469382,00.html }\end{array}$ \\
\hline & TRAINS & $\begin{array}{l}\text { http://databank.worldbank.org/data/reports.aspx?source=UNCTAD- -Trade-Analysis-Information-System- } \\
\text { (TRAINS) }\end{array}$ \\
\hline & NTM-MAP & http://www.cepii.fr/CEPII/en/bdd_modele/presentation.asp?id=28 \\
\hline & I-TIP & https://www.wto.org/english/res_e/statis_e/itip_e.htm \\
\hline & Trade Monitoring & http://tmdb.wto.org/searchmeasures.aspx?lang=en-US \\
\hline & Global Trade Alert & www.globaltradealert.org/ \\
\hline Export subsidies & $\begin{array}{l}\text { Agricultural } \\
\text { Information } \\
\text { Management System }\end{array}$ & http://agims.wto.org/ \\
\hline $\begin{array}{ll}\text { Fossil } & \text { fuel } \\
\text { subsidies }\end{array}$ & IEA's data & http://www.worldenergyoutlook.org/resources/energysubsidies/fossilfuelsubsidydatabase/ \\
\hline $\begin{array}{l}\text { Aggregated } \\
\text { subsidies }\end{array}$ & World Bank's data & http://databank.worldbank.org/data/reports.aspx?source=world-development-indicators \\
\hline $\begin{array}{l}\text { Export } \\
\text { restrictions }\end{array}$ & $\begin{array}{l}\text { OECD's Inventory on } \\
\text { export restrictions }\end{array}$ & $\begin{array}{l}\text { In agriculture } \\
\text { http://qdd.oecd.org/subject.aspx?Subject=ExportRestrictions_PrimaryAgriculture } \\
\text { in minerals, metals and wood } \\
\text { http://qdd.oecd.org/subject.aspx?Subject=ExportRestrictions_IndustrialRawMaterials }\end{array}$ \\
\hline $\begin{array}{l}\text { Trade remedies } \\
\text { (AD, CVD, SFG). }\end{array}$ & TTBD & $\begin{array}{l}\text { http://econ.worldbank.org/WBSITE/EXTERNAL/EXTDEC/EXTRESEARCH/EXTPROGRAMS/EXTTRADERESE } \\
\text { ARCH/0,,contentMDK:22561572 pagePK:64168182 piPK:64168060 theSitePK:544849,00.html }\end{array}$ \\
\hline TBT & TBT-IMS & http://tbtims.wto.org/ \\
\hline SPS & SPS-IMS & http://spsims.wto.org/ \\
\hline TBT and SPS & Perinorm & http://www.perinorm.com/home/default.aspx?ReturnUrl=\%2fdefault.aspx \\
\hline \multirow{3}{*}{$\begin{array}{l}\text { Service trade } \\
\text { restrictiveness } \\
\text { index (STRI) }\end{array}$} & OECD's STRI & http://qdd.oecd.org/subject.aspx?Subject=063bee63-475f-427c-8b50-c19bffa7392d \\
\hline & World Bank's STRI & http://iresearch.worldbank.org/servicetrade/ \\
\hline & Service I-TIP & http://i-tip.wto.org/services/default.aspx \\
\hline \multirow[t]{2}{*}{ Trade facilitation } & Doing Business & http://databank.worldbank.org/data/reports.aspx?source=doing-business \\
\hline & OECD's TFI & http://www.oecd.org/trade/facilitation/indicators.htm. \\
\hline
\end{tabular}




\begin{tabular}{|l|l|l|}
\hline \multirow{2}{*}{$\begin{array}{l}\text { Preferential and } \\
\text { regional } \\
\text { agreements }\end{array}$} & LPI & $\underline{\text { http://lpi.worldbank.org/ }}$ \\
\cline { 2 - 3 } & ETI & https://knoema.com/atlas/sources/WEF?topic=Foreign-Trade \\
\cline { 2 - 3 } & LTA-IS & $\underline{\text { http://rtais.wto.org/UI/PublicMaintainRTAHome.aspx }}$ \\
\cline { 2 - 3 } & Lerch's RTA & $\underline{\text { http://www.ewf.uni-bayreuth.de/en/research/RTA-data/index.html }}$ \\
\cline { 2 - 3 } & WTO's PTA & $\underline{\text { http://kellogg.nd.edu/faculty/fellows/bergstrand.shtml }}$ \\
\cline { 2 - 3 } & GTPA & $\underline{\text { http://ptadb.wto.org/?lang=1 }}$ \\
\cline { 2 - 3 } & DESDA & $\underline{\text { http://wits.worldbank.org/gptad/database_landing.aspx }}$ \\
\hline
\end{tabular}

